\title{
Enantioselective Friedel-Crafts Alkylations with Benzoylhydrazones Promoted by a Simple Strained Silacycle Reagent
}

\author{
Seiji Shirakawa, Richard Berger, and James L. Leighton* \\ Department of Chemistry, Columbia University, New York, New York, 10027
}

\section{Supporting Information}

General Information. All reactions were carried out under an atmosphere of nitrogen in flame- or oven-dried glassware with magnetic stirring unless otherwise indicated. Degassed solvents were purified by passage through an activated alumina column. ${ }^{1} \mathrm{H}$ NMR spectra were recorded on a Bruker DPX-300 $(300 \mathrm{MHz})$ spectrometer and are reported in ppm from $\mathrm{CDCl}_{3}$ internal standard (7.26 ppm). Data are reported as follows: $(\mathrm{s}=$ singlet, br $\mathrm{s}=$ broad singlet, $\mathrm{d}=$ doublet, $\mathrm{t}=$ triplet, $\mathrm{q}=$ quartet, quin $=$ quintet, sep $=$ septet, $\mathrm{m}=$ multiplet, $\mathrm{dd}=$ doublet of doublets, $\mathrm{td}=$ triplet of doublets, $\mathrm{tt}=$ triplet of triplets, $\mathrm{dq}=$ doublet of quartets, $\mathrm{ddt}=$ doublet of doublet of triplets; coupling constant(s) in Hz; integration; assignment). Proton decoupled ${ }^{13} \mathrm{C}$ NMR spectra were recorded on a Bruker DPX-300 (75 MHz) and are reported in ppm from $\mathrm{CDCl}_{3}$ internal standard $(77.0 \mathrm{ppm})$. Infrared spectra were recorded on a Perkin Elmer Paragon 1000 FT-IR spectrometer. Optical rotations were recorded on a Jasco DIP-1000 digital polarimeter.

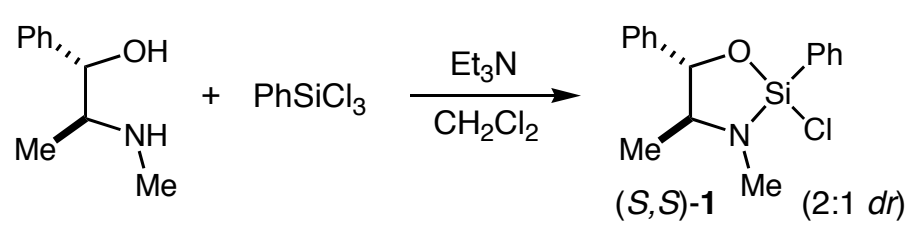

Preparation of reagent $(\boldsymbol{S}, \boldsymbol{S})-\mathbf{1}$ : Triethylamine $(27 \mathrm{~mL}, 0.19 \mathrm{~mol})$ was addded to a cooled $\left(0{ }^{\circ} \mathrm{C}\right)$ solution of phenyltrichlorosilane $(15 \mathrm{~mL}, 0.095 \mathrm{~mol})$ in methylene chloride $(200 \mathrm{~mL})$ under argon. $(1 S, 2 S)$-Pseudoephedrine $(15 \mathrm{~g}, 0.091 \mathrm{~mol})$ was then added portionwise over 15 min maintaining an internal temperature below $15^{\circ} \mathrm{C}$. After stirring with gradual warming to ambient temperature over 12 hours the methylene chloride was removed by distillation. The residue was diluted with pentane $(150 \mathrm{~mL})$ and vigorously stirred for 4 hours to ensure complete precipitation of all triethylamine salts. Filtration of the suspension through a pad of celite and concentration of the filtrate by distillation afforded the crude 
product as a pale-orange oil. Purification by distillation under reduced pressure (bp $\sim 138{ }^{\circ} \mathrm{C}, 0.5 \mathrm{~mm} \mathrm{Hg}$ ) gave $(S, S)-\mathbf{1}\left(\sim 2: 1\right.$ mixture of diastereomers) as a colorless oil $(20 \mathrm{~g}, 75 \%):{ }^{1} \mathrm{H}$ NMR (400 MHz, $\left.\mathrm{CDCl}_{3}\right)$ (major diastereomer) $\delta 7.85(\mathrm{dd}, J=8.0,1.3 \mathrm{~Hz}, 2 \mathrm{H}, \mathrm{Ar}-\mathbf{H}), 7.30-7.56(\mathrm{~m}, 8 \mathrm{H}, \mathrm{Ar}-\mathbf{H}), 4.73(\mathrm{~d}, J=8.3 \mathrm{~Hz}$, 1H, PhCH-O), 3.17 (dq, $\left.J=8.3,6.0 \mathrm{~Hz}, 1 \mathrm{H}, \mathrm{CH}_{3} \mathrm{CH}-\mathrm{N}\right), 2.53\left(\mathrm{~s}, 3 \mathrm{H}, \mathrm{CH}_{3}-\mathrm{N}\right), 1.20(\mathrm{~d}, J=6.0 \mathrm{~Hz}, 3 \mathrm{H}$, $\mathrm{CH}_{3}-\mathrm{CHN}$ ); (minor diastereomer) $\delta 7.97$ (dd, $\left.J=8.0,1.4 \mathrm{~Hz}, 2 \mathrm{H}, \mathrm{Ar}-\mathbf{H}\right), 7.30-7.56$ (m, 8H, Ar-H), 4.86 $(\mathrm{d}, J=7.2 \mathrm{~Hz}, 1 \mathrm{H}, \mathrm{PhCH}-\mathrm{O}), 3.34$ (q, $\left.J=6.2 \mathrm{~Hz}, 1 \mathrm{H}, \mathrm{CH}_{3} \mathrm{CH}-\mathrm{N}\right), 2.53\left(\mathrm{~s}, 3 \mathrm{H}, \mathrm{CH}_{3}-\mathrm{N}\right), 1.26(\mathrm{~d}, J=6.1$ $\left.\mathrm{Hz}, 3 \mathrm{H}, \mathrm{CH}_{3}-\mathrm{CHN}\right) ;{ }^{13} \mathrm{C}$ NMR $\left(100 \mathrm{MHz}, \mathrm{CDCl}_{3}\right) \delta 141.0,140.6,134.8,134.7,131.55,131.48,130.1$, $128.2,128.0,127.94,127.87,127.8,126.6,126.2,125.8,85.8,84.2,63.9,62.8,29.7,29.4,17.4,16.8 ;{ }^{29} \mathrm{Si}$ NMR (60 MHz, $\left.\mathrm{CDCl}_{3}\right) \delta-12.44$ (major diastereomer) and -13.85 (minor diastereomer); IR $\left(\mathrm{CHCl}_{3}\right)$ $3074,3033,2971,2890,2812,1592,1492,1448,1431,1373,1280,1215,1189,1122 \mathrm{~cm}^{-1}$.

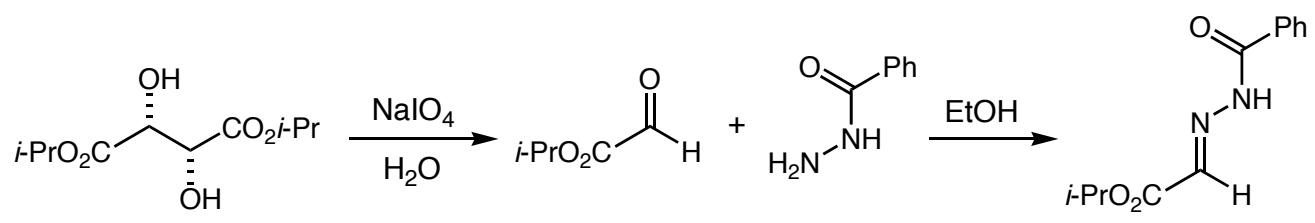

Preparation of (benzoyl-hydrazono)-acetic acid iso-propyl ester: To a cooled $\left(0^{\circ} \mathrm{C}\right)$ solution of diiso-propyl L-tartrate $(9.37 \mathrm{~g}, 40.0 \mathrm{mmol})$ in $\mathrm{H}_{2} \mathrm{O}(20 \mathrm{~mL})$ was added dropwise a solution of $\mathrm{NaIO}_{4}(11.1$ $\mathrm{g}, 52.0 \mathrm{mmol})$ in $\mathrm{H}_{2} \mathrm{O}(50 \mathrm{~mL})$, and the resulting mixture was stirred for $2 \mathrm{~h}$ at $0{ }^{\circ} \mathrm{C}$. The reaction mixture was extracted with EtOAc $(5 \times 50 \mathrm{~mL})$. The combined organic layers were dried $\left(\mathrm{MgSO}_{4}\right)$, filtered, and concentrated. To a solution of the residue in $80 \mathrm{~mL}$ of $\mathrm{EtOH}$, was added benzoic hydrazide $(8.71 \mathrm{~g}, 64.0$ $\mathrm{mmol}$ ). The resulting suspension was vigorously stirred for $12 \mathrm{~h}$. The reaction mixture was concentrated and the residue wastreated with hexanes $(100 \mathrm{~mL})$. The resulting suspension was filtered with hexanes washes. The resulting solid was collected and dried to give (benzoyl-hydrazono)-acetic acid isopropyl ester (14.8 g, $63.3 \mathrm{mmol}$, (99\% yield, based on benzoic hydrazide)) as a white solid. ${ }^{1} \mathrm{H}$ NMR (300 MHz, $\left.\mathrm{CDCl}_{3}\right) \delta 9.90$ (br s, 1H, NH), 8.12 (br s, $\left.1 \mathrm{H}, \mathrm{CH}=\mathrm{N}\right), 7.87$ (d, 2H, J= $\left.7.4 \mathrm{~Hz}, \mathrm{Ar}-\mathbf{H}\right), 7.55(\mathrm{t}, 1 \mathrm{H}, J=7.4$ $\mathrm{Hz}, \mathrm{Ar}-\mathbf{H}), 7.44$ (t, 2H, J=7.4 Hz, Ar-H), $5.17\left(\mathrm{sep}, 1 \mathrm{H}, J=6.2 \mathrm{~Hz},\left(\mathrm{CH}_{3}\right)_{2} \mathrm{CH}\right), 1.32(\mathrm{~d}, 6 \mathrm{H}, J=6.2 \mathrm{~Hz}$, $\left.\left(\mathrm{CH}_{3}\right)_{2} \mathrm{CH}\right)$; IR (thin film) 3424, 1714, 1665, 1598, 1262, 1147, $1102 \mathrm{~cm}^{-1}$; HRMS (FAB+) calcd for $\mathrm{C}_{12} \mathrm{H}_{15} \mathrm{~N}_{2} \mathrm{O}_{3}: 235.1083\left([\mathrm{M}+\mathrm{H}]^{+}\right)$, found $235.1090\left([\mathrm{M}+\mathrm{H}]^{+}\right)$. 


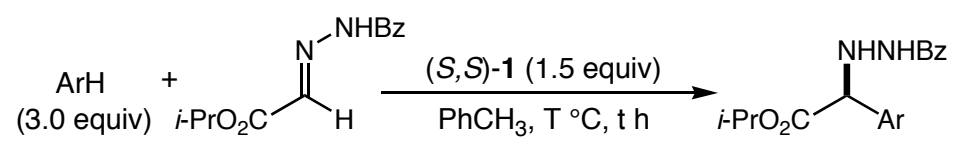

General procedure for the enantioselective Friedel-Crafts reactions in Table 1: To a solution of (benzoyl-hydrazono)-acetic acid iso-propyl ester $(0.200 \mathrm{mmol})$ and $(S, S)-\mathbf{1}(91.2 \mathrm{mg}, 0.300 \mathrm{mmol})$ in toluene $(2 \mathrm{~mL})$ is added the arene $(0.600 \mathrm{mmol})$ and the resulting mixture is stirred at the indicated temperature and time (see Table 1 and Table 2). The reaction is quenched with $\mathrm{H}_{2} \mathrm{O}(5 \mathrm{~mL})$ and the resulting mixture is stirred for $15 \mathrm{~min}$, and then diluted with EtOAc $(5 \mathrm{~mL})$. The phases are separated, and the aqueous layer is extracted with EtOAc $(2 \times 5 \mathrm{~mL})$. The combined organic layers are dried $\left(\mathrm{MgSO}_{4}\right)$, filtered and concentrated. Purification by flash chromatography on silica gel affords the pure products.

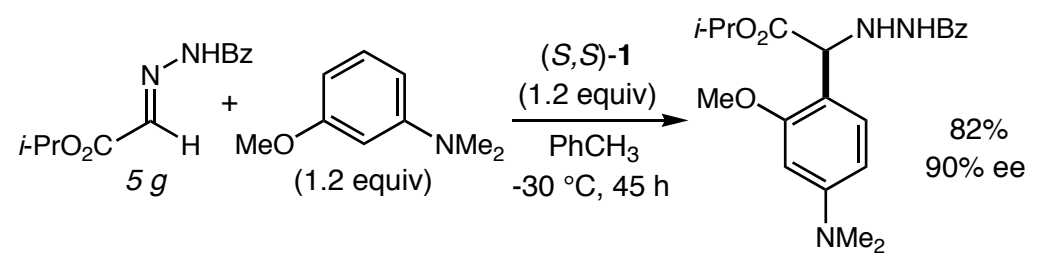

Procedure for larger scale reaction described in Scheme 3: To a cooled $\left(-30{ }^{\circ} \mathrm{C}\right)$ solution of $(S, S)-1$ $(7.78 \mathrm{~g}, 25.6 \mathrm{mmol})$ in toluene $(200 \mathrm{~mL})$ was added (benzoyl-hydrazono)-acetic acid iso-propyl ester (5.00 g, $21.3 \mathrm{mmol})$. After $15 \mathrm{~min}, 3$-dimethylaminoanisole $(3.75 \mathrm{~mL}, 25.6 \mathrm{mmol})$ was added dropwise. The reaction mixture was maintained at $-30{ }^{\circ} \mathrm{C}$ for $45 \mathrm{~h}$, then quenched with $\mathrm{H}_{2} \mathrm{O}(150 \mathrm{~mL})$. After 30 min, the solution was filtrated and the phases of filtrate were separated, and the aqueous layer was extracted with EtOAc $(2 \times 100 \mathrm{~mL})$. The combined organic layers were washed with $\mathrm{H}_{2} \mathrm{O}(100 \mathrm{~mL})$, and then dried $\left(\mathrm{MgSO}_{4}\right)$, filtered, and concentrated. The resulting residue was purified by flash chromatography on silica gel (hexane/EtOAc $4 / 1$ to $2 / 1$ as eluent) to yield ( $N$ '-benzoyl-hydrazino)-(4-dimethylamino-2-methoxyphenyl)-acetic acid iso-propyl ester as a slightly yellow solid (6.73 g, $17.5 \mathrm{mmol}, 82 \%$ yield). The pseudoephedrine was recovered by the following procedure: the combined aqueous extracts from the above workup were basified with $1 N$ aqueous $\mathrm{NaOH}(100 \mathrm{~mL})$ and the cloudy suspension was extracted with EtOAc (3 x $100 \mathrm{~mL})$. The combined organic layers were washed with $\mathrm{H}_{2} \mathrm{O}(50 \mathrm{~mL})$ and brine $(100$ $\mathrm{mL})$, and then dried $\left(\mathrm{MgSO}_{4}\right)$, filtered and concentrated to yield $(S, S)$-pseudoephedrine as a white solid (4.19 g, $25.4 \mathrm{mmol}, 99 \%$ recovery based on amount of $\mathbf{1}$ employed)). 

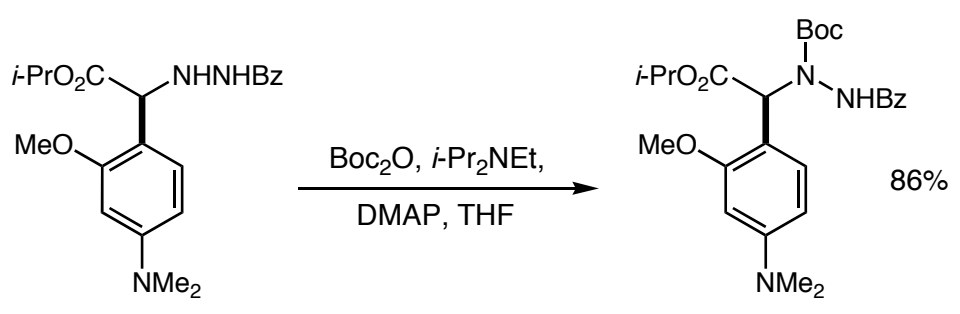

To a solution of ( $N$ '-benzoyl-hydrazino)-(4-dimethylamino-2-methoxy-phenyl)-acetic acid iso-propyl ester $(0.385 \mathrm{~g}, 1.00 \mathrm{mmol})$ and $i-\mathrm{Pr}_{2} \mathrm{NEt}(0.348 \mathrm{ml}, 2.00 \mathrm{mmol})$ in THF $(10 \mathrm{~mL})$ was added a solution of $\mathrm{Boc}_{2} \mathrm{O}(0.437 \mathrm{~g}, 2.00 \mathrm{mmol})$ in THF $(20 \mathrm{~mL})$, and 4-(dimethylamino)pyridine $(24.4 \mathrm{mg}, 0.200 \mathrm{mmol})$. After $30 \mathrm{~min}$, the reaction was quenched by the addition of $\mathrm{H}_{2} \mathrm{O}(20 \mathrm{~mL})$ and the mixture was concentrated to remove the THF. The residue was extracted with $\mathrm{CH}_{2} \mathrm{Cl}_{2}(3 \times 10 \mathrm{~mL})$, and the combined organic layers were dried $\left(\mathrm{MgSO}_{4}\right)$, filtered, and concentrated. The resulting residue was purified by flash chromatography on silica gel (hexane/EtOAc $5 / 1 \sim 3 / 1$ as eluent) to yield ( $N$-benzoyl- $N$-tertbutoxycarbonyl-hydrazino)-(4-dimethylamino-phenyl)-acetic acid iso-propyl ester (0.418 g, $0.861 \mathrm{mmol}$, $86 \%$ yield $) .[\alpha]^{28}{ }_{D}=+44.7^{\circ}\left(c 1.1, \mathrm{CHCl}_{3}\right) ;{ }^{1} \mathrm{H} \mathrm{NMR}\left(300 \mathrm{MHz}, \mathrm{CDCl}_{3}\right) \delta$ 7.89-7.97 (br m, 1H, NHBz), 7.35-7.54 (br m, 5H, Ar-H), 7.03-7.13 (m, 1H, Ar-H), 5.90-6.21 (m, 2H + 1H, Ar-H + CHN), 5.11 (sep, $\left.1 \mathrm{H}, J=6.1 \mathrm{~Hz},\left(\mathrm{CH}_{3}\right)_{2} \mathrm{CH}\right), 3.52-3.78$ (br m, 3H, OCH $), 2.90-2.96\left(\mathrm{~m}, 6 \mathrm{H}, \mathrm{N}\left(\mathrm{CH}_{3}\right)_{2}\right), 1.46-1.53(\mathrm{~m}, 9 \mathrm{H}$, $\left.\left(\mathrm{CH}_{3}\right)_{3} \mathrm{C}\right), 1.23-1.25\left(\mathrm{~m}, 3 \mathrm{H},\left(\mathrm{CH}_{3}\right)_{2} \mathrm{CH}\right), 1.19\left(\mathrm{~d}, 3 \mathrm{H}, J=6.1 \mathrm{~Hz},\left(\mathrm{CH}_{3}\right)_{2} \mathrm{CH}\right)$; IR (thin film) 3402, 3323, $2980,2931,1734,1700,1617,1523,1366,1249,1165,1106,979,714 \mathrm{~cm}^{-1}$; LRMS (FAB+) calcd for $\mathrm{C}_{26} \mathrm{H}_{35} \mathrm{~N}_{3} \mathrm{O}_{6}: 485\left(\mathrm{M}^{+}\right)$, found $485\left(\mathrm{M}^{+}\right)$.
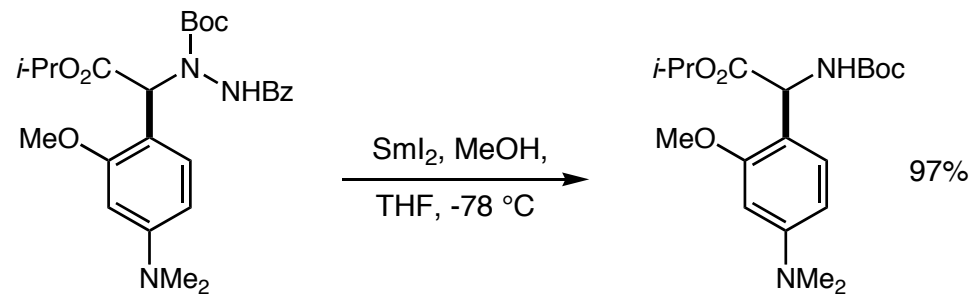

To a cooled $\left(-78{ }^{\circ} \mathrm{C}\right)$ degassed solution of ( $N^{\prime}$-benzoyl- $N$-tert-butoxycarbonyl-hydrazino)-(4dimethylamino-phenyl)-acetic acid iso-propyl ester $(0.388 \mathrm{~g}, 0.800 \mathrm{mmol})$ in $\mathrm{MeOH}(8 \mathrm{~mL})$ was added $\mathrm{SmI}_{2}$ (17.6 mL, $1.76 \mathrm{mmol}, 0.1 \mathrm{M}$ in THF). After $30 \mathrm{~min}$, the reaction mixture was concentrated. The residue was purified by flash chromatography on silica gel (hexane/EtOAc 5/1 as eluent) to give tert- 
butoxycarbonylamino-(4-dimethylamino-2-methoxy-phenyl)-acetic acid ethyl ester (0.284 g, $0.775 \mathrm{mmol}$, 97\% yield). The enantiomeric excess was checked by HPLC (DAICEL Chiralpak AD-H, hexane/i-PrOH $=90 / 10,1.0 \mathrm{~mL} / \mathrm{min}$, retention time $=15.0$ (minor) and 21.7 (major) $\mathrm{min}$ ) and found to be $90 \%$ ee,

establishing that the Boc protection and $\mathrm{SmI}_{2}$ reduction proceded without racemization. $[\alpha]^{28}=+142.8^{\circ}$ $\left(c 0.51, \mathrm{CHCl}_{3}\right) ;{ }^{1} \mathrm{H} \mathrm{NMR}\left(300 \mathrm{MHz}, \mathrm{CDCl}_{3}\right) \delta 7.10(\mathrm{~d}, 1 \mathrm{H}, J=8.3 \mathrm{~Hz}, \mathrm{Ar}-\mathbf{H}), 6.24(\mathrm{dd}, 1 \mathrm{H}, J=2.3,8.3$ $\mathrm{Hz}, \operatorname{Ar}-\mathbf{H}), 6.18$ (d, 1H, $J=2.3 \mathrm{~Hz}, \operatorname{Ar}-\mathbf{H}), 5.48$ (br d, 1H, $J=8.7 \mathrm{~Hz}, \mathrm{NH}), 5.27$ (d, $1 \mathrm{H}, J=8.7 \mathrm{~Hz}$, $\mathrm{CHN}), 5.01\left(\mathrm{sep}, 1 \mathrm{H}, J=6.2 \mathrm{~Hz},\left(\mathrm{CH}_{3}\right)_{2} \mathrm{CH}\right), 3.78\left(\mathrm{~s}, 3 \mathrm{H}, \mathrm{OCH}_{3}\right), 2.95\left(\mathrm{~s}, 6 \mathrm{H}, \mathrm{N}\left(\mathrm{CH}_{3}\right)_{2}\right), 1.43(\mathrm{~s}, 9 \mathrm{H}$, $\left.\left(\mathrm{CH}_{3}\right)_{3} \mathrm{C}\right), 1.20\left(\mathrm{~d}, 3 \mathrm{H}, J=6.2 \mathrm{~Hz},\left(\mathrm{CH}_{3}\right)_{2} \mathrm{CH}\right), 1.10\left(\mathrm{~d}, 3 \mathrm{H}, J=6.2 \mathrm{~Hz},\left(\mathrm{CH}_{3}\right)_{2} \mathrm{CH}\right) ;{ }^{13} \mathrm{C} \mathrm{NMR}(75 \mathrm{MHz}$, $\left.\mathrm{CDCl}_{3}\right) \delta 171.6,157.8,155.4,151.8,130.7,114.3,104.4,95.7,79.4,68.6,55.0,54.4,40.6,28.4,21.7$, 21.4; IR (thin film) 3451, 3372, 2980, 2931, 1734, 1715, 1617, 1519, 1489, 1366, 1244, 1170, 1106, 1053, 1028, 979, $812 \mathrm{~cm}^{-1}$; LRMS (FAB+) calcd for $\mathrm{C}_{19} \mathrm{H}_{30} \mathrm{~N}_{2} \mathrm{O}_{5}: 366\left(\mathrm{M}^{+}\right)$, found $366\left(\mathrm{M}^{+}\right)$.

\section{Characterization data for the products in Table 1 and Table 2:}

Table 1, Entry 1: (S)-(N'-Benzoyl-hydrazino)-(4-dimethylamino-phenyl)-acetic acid iso-propyl ester: (95\% ee, see below for assay) $[\alpha]^{26}=+103.4^{\circ}\left(c 1.0, \mathrm{CHCl}_{3}\right) ;{ }^{1} \mathrm{H} \mathrm{NMR}\left(300 \mathrm{MHz}, \mathrm{CDCl}_{3}\right) \delta 7.87$ (br s, 1H, NHBz), 7.68 (d, 2H, J=7.3 Hz, Ar-H), 7.49 (t, 1H, J=7.3 Hz, Ar-H), $7.40(\mathrm{t}, 2 \mathrm{H}, J=7.3 \mathrm{~Hz}$, Ar-H), $7.28(\mathrm{~d}, 2 \mathrm{H}, J=8.7 \mathrm{~Hz}, \operatorname{Ar}-\mathbf{H}), 6.68(\mathrm{~d}, 2 \mathrm{H}, J=8.7 \mathrm{~Hz}, \operatorname{Ar}-\mathbf{H}), 5.16$ (br s, 1H, CHNH), 5.06 (sep, $\left.1 \mathrm{H}, J=6.2 \mathrm{~Hz},\left(\mathrm{CH}_{3}\right)_{2} \mathrm{CH}\right), 4.75(\mathrm{~s}, 1 \mathrm{H}, \mathrm{CHNH}), 2.95\left(\mathrm{~s}, 6 \mathrm{H}, \mathrm{N}\left(\mathrm{CH}_{3}\right)_{2}\right), 1.24(\mathrm{~d}, 3 \mathrm{H}, J=6.2 \mathrm{~Hz}$, $\left.\left(\mathrm{CH}_{3}\right)_{2} \mathrm{CH}\right), 1.13\left(\mathrm{~d}, 3 \mathrm{H}, J=6.2 \mathrm{~Hz},\left(\mathrm{CH}_{3}\right)_{2} \mathrm{CH}\right) ;{ }^{13} \mathrm{C} \mathrm{NMR}\left(75 \mathrm{MHz}, \mathrm{CDCl}_{3}\right) \delta$ 171.6, 167.0, 150.6, 132.7, 131.9, 129.2, 128.7, 126.9, 122.8, 112.3, 68.7, 66.8, 40.4, 21.7, 21.5; IR (thin film) 3299, 2980, 2927, 2803, 1728, 1648, 1612, 1524, 1453, 1355, 1222, 1195, 1107, 814, 708, $690 \mathrm{~cm}^{-1}$; HRMS (FAB+) calcd for $\mathrm{C}_{20} \mathrm{H}_{24} \mathrm{~N}_{3} \mathrm{O}_{3}: 354.1818\left([\mathrm{M}-\mathrm{H}]^{+}\right)$, found $354.1826\left([\mathrm{M}-\mathrm{H}]^{+}\right)$.

Table 1, Entry 2: (S)-(N'-Benzoyl-hydrazino)-(4-diethylamino-phenyl)-acetic acid iso-propyl ester: (94\% ee, see below for assay) $[\alpha]^{26}{ }_{\mathrm{D}}=+111.1^{\circ}\left(c 1.0, \mathrm{CHCl}_{3}\right) ;{ }^{1} \mathrm{H} \mathrm{NMR}\left(300 \mathrm{MHz}, \mathrm{CDCl}_{3}\right) \delta 8.13$ (br s, 1H, NHBz), 7.73 (d, 2H, $J=7.3 \mathrm{~Hz}, \operatorname{Ar}-\mathbf{H}), 7.50$ (t, 1H, J=7.3 Hz, Ar-H), 7.42 (t, 2H, $J=7.3 \mathrm{~Hz}$, Ar-H), 7.24 (d, 2H, $J=8.7 \mathrm{~Hz}, \operatorname{Ar}-\mathbf{H}), 6.62$ (d, 2H, $J=8.7 \mathrm{~Hz}, \operatorname{Ar}-\mathbf{H}), 5.13$ (br s, 1H, CHNH), 5.07 (sep, $\left.1 \mathrm{H}, J=6.3 \mathrm{~Hz},\left(\mathrm{CH}_{3}\right)_{2} \mathrm{CH}\right), 4.75(\mathrm{~s}, 1 \mathrm{H}, \mathrm{CHNH}), 3.34\left(\mathrm{q}, 4 \mathrm{H}, J=7.1 \mathrm{~Hz}, \mathrm{~N}\left(\mathrm{CH}_{2} \mathrm{CH}_{3}\right)_{2}\right), 1.23(\mathrm{~d}, 3 \mathrm{H}, J=$ $\left.6.3 \mathrm{~Hz},\left(\mathrm{CH}_{3}\right)_{2} \mathrm{CH}\right), 1.15\left(\mathrm{t}, 6 \mathrm{H}, J=7.1 \mathrm{~Hz}, \mathrm{~N}\left(\mathrm{CH}_{2} \mathrm{CH}_{3}\right)_{2}\right), 1.14\left(\mathrm{~d}, 3 \mathrm{H}, J=6.3 \mathrm{~Hz},\left(\mathrm{CH}_{3}\right)_{2} \mathrm{CH}\right) ;{ }^{13} \mathrm{C} \mathrm{NMR}$ 
$\left(75 \mathrm{MHz}, \mathrm{CDCl}_{3}\right) \delta 171.7,167.0,147.9,132.7,131.8,129.4,128.6,126.9,121.5,111.5,68.6,66.8,44.2$, 21.7, 21.5, 12.5; IR (thin film) 3283, 2978, 2929, 1727, 1657, 1612, 1521, 1270, 1200, 1105, 813, 697 $\mathrm{cm}^{-1}$; LRMS (FAB+) calcd for $\mathrm{C}_{22} \mathrm{H}_{28} \mathrm{~N}_{3} \mathrm{O}_{3}: 382\left([\mathrm{M}-\mathrm{H}]^{+}\right)$, found $382\left([\mathrm{M}-\mathrm{H}]^{+}\right)$.

Table 1, Entry 3: (S)-(N'-Benzoyl-hydrazino)-(4-pyrrolidin-1-yl-phenyl)-acetic acid iso-propyl ester: (93\% ee, see below for assay) $[\alpha]^{26}=+112.6^{\circ}\left(c 1.0, \mathrm{CHCl}_{3}\right) ;{ }^{1} \mathrm{H} \mathrm{NMR}\left(300 \mathrm{MHz}, \mathrm{CDCl}_{3}\right) \delta 7.85$ (br s, 1H, NHBz), 7.68 (d, 2H, $J=7.2 \mathrm{~Hz}, \operatorname{Ar}-\mathbf{H}), 7.49$ (t, 1H, $J=7.2 \mathrm{~Hz}, \operatorname{Ar}-\mathbf{H}), 7.40$ (t, 2H, $J=7.2 \mathrm{~Hz}$, $\operatorname{Ar}-\mathbf{H}), 7.26$ (d, 2H, $J=8.6 \mathrm{~Hz}, \operatorname{Ar}-\mathbf{H}), 6.51$ (d, 2H, J = 8.6 Hz, Ar-H), 5.14 (br s, 1H, CHNH), 5.06 (sep, $\left.1 \mathrm{H}, J=6.2 \mathrm{~Hz},\left(\mathrm{CH}_{3}\right)_{2} \mathrm{CH}\right), 4.73(\mathrm{~s}, 1 \mathrm{H}, \mathrm{CHNH}), 3.28\left(\mathrm{t}, 4 \mathrm{H}, J=6.5 \mathrm{~Hz}, \mathrm{NCH}_{2} \mathrm{CH}_{2}\right), 1.95-2,04(\mathrm{~m}, 4 \mathrm{H}$, $\left.\mathrm{NCH}_{2} \mathrm{CH}_{2}\right), 1.22\left(\mathrm{~d}, 3 \mathrm{H}, J=6.2 \mathrm{~Hz},\left(\mathrm{CH}_{3}\right)_{2} \mathrm{CH}\right), 1.13\left(\mathrm{~d}, 3 \mathrm{H}, J=6.2 \mathrm{~Hz},\left(\mathrm{CH}_{3}\right)_{2} \mathrm{CH}\right) ;{ }^{13} \mathrm{C} \mathrm{NMR}(75 \mathrm{MHz}$, $\left.\mathrm{CDCl}_{3}\right) \delta 171.7,167.0,147.9,132.7,131.6,129.2,128.5,127.0,121.6,111.4,68.5,66.8,47.4,25.4,21.6$, 21.4; IR (thin film) 3294, 2977, 2933, 2837, 1727, 1614, 1523, 1375, 1182, 1107, 813, $694 \mathrm{~cm}^{-1}$; HRMS $(\mathrm{FAB}+)$ calcd for $\mathrm{C}_{22} \mathrm{H}_{26} \mathrm{~N}_{3} \mathrm{O}_{3}: 380.1974\left([\mathrm{M}-\mathrm{H}]^{+}\right)$, found $380.1977\left([\mathrm{M}-\mathrm{H}]^{+}\right)$.

Table 1, Entry 4: (S)-(N'-Benzoyl-hydrazino)-(4-dimethylamino-2-methyl-phenyl)-acetic acid iso-propyl ester: (87\% ee, see below for assay) $\left.[\alpha]_{\mathrm{D}}^{24}=+84.1^{\circ}(c) 1.0, \mathrm{CHCl}_{3}\right) ;{ }^{1} \mathrm{H}$ NMR $(300 \mathrm{MHz}$, $\mathrm{CDCl}_{3}$ ) 7.91 (br s, 1H, NHBz), 7.69 (d, 2H, J=7.3 Hz, Ar-H), 7.49 (t, 1H, J = 7.3 Hz, Ar-H), 7.40 (t, $2 \mathrm{H}, J=7.3 \mathrm{~Hz}, \operatorname{Ar}-\mathbf{H}), 7.28(\mathrm{~d}, 1 \mathrm{H}, J=9.3 \mathrm{~Hz}, \operatorname{Ar}-\mathbf{H}), 6.50-6.54(\mathrm{~m}, 2 \mathrm{H}, \mathrm{Ar}-\mathbf{H}), 5.07$ (sep, 1H, $J=6.3$ $\left.\mathrm{Hz},\left(\mathrm{CH}_{3}\right)_{2} \mathrm{CH}\right), 5.04$ (br s, 1H, CHNH), 4.96 (s, 1H, CHNH), 2.94 (s, 6H, N(CH $\left.)_{2}\right), 2.48$ (s, 3H, Ar$\left.\mathrm{CH}_{3}\right), 1.22\left(\mathrm{~d}, 3 \mathrm{H}, J=6.3 \mathrm{~Hz},\left(\mathrm{CH}_{3}\right)_{2} \mathrm{CH}\right), 1.13\left(\mathrm{~d}, 3 \mathrm{H}, J=6.3 \mathrm{~Hz},\left(\mathrm{CH}_{3}\right)_{2} \mathrm{CH}\right) ;{ }^{13} \mathrm{C} \mathrm{NMR}(75 \mathrm{MHz}$, $\left.\mathrm{CDCl}_{3}\right) \delta 171.9,166.8,150.2,137.9,132.6,131.6,128.7,128.5,126.8,121.4,114.2,110.1,68.7,63.7$, 40.5, 21.9, 21.7, 20.1; IR (thin film) 3295, 2980, 2929, 1726, 1650, 1611, 1515, 1454, 1357, 1215, 1106, $696 \mathrm{~cm}^{-1}$; HRMS (FAB+) calcd for $\mathrm{C}_{21} \mathrm{H}_{26} \mathrm{~N}_{3} \mathrm{O}_{3}: 368.1974\left([\mathrm{M}-\mathrm{H}]^{+}\right)$, found $368.1974\left([\mathrm{M}-\mathrm{H}]^{+}\right)$.

Table 1, Entry 5: (S)-(N'-Benzoyl-hydrazino)-(4-dimethylamino-2-methoxy-phenyl)-acetic acid iso-propyl ester: (90\% ee, see below for assay) $[\alpha]^{26}=+90.2^{\circ}\left(c\right.$ 1.0, $\left.\mathrm{CHCl}_{3}\right) ;{ }^{1} \mathrm{H}$ NMR $(300 \mathrm{MHz}$, $\left.\mathrm{CDCl}_{3}\right) \delta 8.06$ (br s, 1H, NHBz), $7.70(\mathrm{~d}, 2 \mathrm{H}, J=7.1 \mathrm{~Hz}, \mathrm{Ar}-\mathrm{H}), 7.49$ (t, 1H, J= 7.1 Hz, Ar-H), 7.40 (t, $2 \mathrm{H}, J=7.1 \mathrm{~Hz}, \operatorname{Ar}-\mathbf{H}), 7.13(\mathrm{~d}, 1 \mathrm{H}, J=8.4 \mathrm{~Hz}, \operatorname{Ar}-\mathbf{H}), 6.26(\mathrm{dd}, 1 \mathrm{H}, J=2.1,8.4 \mathrm{~Hz}, \operatorname{Ar}-\mathbf{H}), 6.21(\mathrm{~d}, 1 \mathrm{H}$, $J=2.1 \mathrm{~Hz}, \mathrm{Ar}-\mathbf{H}), 5.36$ (br s, 1H, CHNH), 5.11 (sep, 1H, J=6.3 Hz, $\left.\left(\mathrm{CH}_{3}\right)_{2} \mathrm{CH}\right), 4.92$ (s, 1H, CHNH), $3.83\left(\mathrm{~s}, 3 \mathrm{H}, \mathrm{OCH}_{3}\right), 2.97\left(\mathrm{~s}, 6 \mathrm{H}, \mathrm{N}\left(\mathrm{CH}_{3}\right)_{2}\right), 1.22\left(\mathrm{~d}, 3 \mathrm{H}, J=6.3 \mathrm{~Hz},\left(\mathrm{CH}_{3}\right)_{2} \mathrm{CH}\right), 1.18(\mathrm{~d}, 3 \mathrm{H}, J=6.3 \mathrm{~Hz}$, 
$\left.\left(\mathrm{CH}_{3}\right)_{2} \mathrm{CH}\right) ;{ }^{13} \mathrm{C}$ NMR $\left(75 \mathrm{MHz}, \mathrm{CDCl}_{3}\right) \delta 172.2,166.3,158.4,152.1,133.0,131.6,130.9,128.5,126.8$, 111.8, 104.3, 95.6, 68.4, 62.4, 55.3, 40.4, 21.7, 21.5; IR (thin film) 3291, 2980, 2936, 1728, 1652, 1617, $1572,1519,1457,1359,1244,1102,1031,978,814,699 \mathrm{~cm}^{-1}$; HRMS (FAB+) calcd for $\mathrm{C}_{21} \mathrm{H}_{26} \mathrm{~N}_{3} \mathrm{O}_{4}$ : $384.1923\left([\mathrm{M}-\mathrm{H}]^{+}\right)$, found $384.1930\left([\mathrm{M}-\mathrm{H}]^{+}\right)$.

Table 1, Entry 6: (S)-(N'-Benzoyl-hydrazino)-(4-dimethylamino-2-methylsulfanyl-phenyl)-acetic acid iso-propyl ester: (88\% ee, see below for assay) $[\alpha]^{25}=+83.1^{\circ}\left(c 1.0, \mathrm{CHCl}_{3}\right) ;{ }^{1} \mathrm{H} \mathrm{NMR}(300 \mathrm{MHz}$, $\mathrm{CDCl}_{3}$ ) 7.96 (br s, 1H, NHBz), 7.78 (d, 2H, $\left.J=7.3 \mathrm{~Hz}, \mathrm{Ar}-\mathbf{H}\right), 7.46$ (t, 1H, $\left.J=7.3 \mathrm{~Hz}, \mathrm{Ar}-\mathbf{H}\right), 7.38$ (t, $2 \mathrm{H}, J=7.3 \mathrm{~Hz}, \mathrm{Ar}-\mathbf{H}), 7.20(\mathrm{~d}, 1 \mathrm{H}, J=8.6 \mathrm{~Hz}, \operatorname{Ar}-\mathbf{H}), 6.71(\mathrm{~d}, 1 \mathrm{H}, J=2.6 \mathrm{~Hz}, \operatorname{Ar}-\mathbf{H}), 6.51(\mathrm{dd}, 1 \mathrm{H}, J=$ 2.6, 8.6 Hz, Ar-H), 5.36 (br s, 1H, CHNH), 5.35 (s, 1H, CHNH), 5.07 (sep, $1 \mathrm{H}, J=6.3 \mathrm{~Hz},\left(\mathrm{CH}_{3}\right)_{2} \mathrm{CH}$ ), $2.95\left(\mathrm{~s}, 6 \mathrm{H}, \mathrm{N}\left(\mathrm{CH}_{3}\right)_{2}\right), 2.47$ (s, 3H, SCH$), 1.23\left(\mathrm{~d}, 3 \mathrm{H}, J=6.3 \mathrm{~Hz},\left(\mathrm{CH}_{3}\right)_{2} \mathrm{CH}\right), 1.13(\mathrm{~d}, 3 \mathrm{H}, J=6.3 \mathrm{~Hz}$, $\left.\left(\mathrm{CH}_{3}\right)_{2} \mathrm{CH}\right) ;{ }^{13} \mathrm{C} \mathrm{NMR}\left(75 \mathrm{MHz}, \mathrm{CDCl}_{3}\right) \delta 171.7,166.6,150.6,138.9,132.8,131.6,129.2,128.5,126.9$, 122.9, 113.0, 110.6, 68.7, 63.7, 40.2, 21.7, 21.4, 18.2; IR (thin film) 3289, 2980, 2921, 1727, 1654, 1600, 1506, 1456, 1356, 1220, 1106, 711, $694 \mathrm{~cm}^{-1}$; LRMS (FAB+) calcd for $\mathrm{C}_{21} \mathrm{H}_{26} \mathrm{~N}_{3} \mathrm{O}_{3} \mathrm{~S}: 400\left([\mathrm{M}-\mathrm{H}]^{+}\right)$, found $400\left([\mathrm{M}-\mathrm{H}]^{+}\right)$.

Table 1, Entry 7: $(S)$-( $N$ '-Benzoyl-hydrazino)-(1-methyl-2,3-dihydro-1 $H$-indol-5-yl)-acetic acid iso-propyl ester: (90\% ee, see below for assay) $[\alpha]^{24}{ }_{\mathrm{D}}=+98.2^{\circ}\left(c 1.0, \mathrm{CHCl}_{3}\right) ;{ }^{1} \mathrm{H}$ NMR $(300 \mathrm{MHz}$, $\left.\mathrm{CDCl}_{3}\right) \delta 8.17$ (br s, 1H, NHBz), $7.71(\mathrm{~d}, 2 \mathrm{H}, J=7.2 \mathrm{~Hz}, \mathrm{Ar}-\mathrm{H}), 7.48$ (t, 1H, $\left.J=7.2 \mathrm{~Hz}, \mathrm{Ar}-\mathrm{H}\right), 7.39$ (t, $2 \mathrm{H}, J=7.2 \mathrm{~Hz}, \operatorname{Ar}-\mathbf{H}), 7.10$ (s, 1H, Ar-H ), 7.08 (d, 1H, $J=7.8 \mathrm{~Hz}, \operatorname{Ar}-\mathbf{H}), 6.38$ (d, 1H, $J=7.8 \mathrm{~Hz}, \mathrm{Ar}-$ H), 5.11 (br s, 1H, CHNH), $5.06\left(\mathrm{sep}, 1 \mathrm{H}, J=6.3 \mathrm{~Hz},\left(\mathrm{CH}_{3}\right)_{2} \mathrm{CH}\right), 4.72(\mathrm{~s}, 1 \mathrm{H}, \mathrm{CHNH}), 3.30$ (t, $2 \mathrm{H}, J=$ $\left.8.2 \mathrm{~Hz}, \mathrm{Ar}-\mathrm{CH}_{2} \mathrm{CH}_{2} \mathrm{~N}\right), 2.90\left(\mathrm{t}, 2 \mathrm{H}, J=8.2 \mathrm{~Hz}, \mathrm{Ar}-\mathrm{CH}_{2} \mathrm{CH}_{2} \mathrm{~N}\right), 2.74\left(\mathrm{~s}, 3 \mathrm{H}, \mathrm{NCH}_{3}\right), 1.22(\mathrm{~d}, 3 \mathrm{H}, J=6.3$ $\left.\mathrm{Hz},\left(\mathrm{CH}_{3}\right)_{2} \mathrm{CH}\right), 1.13\left(\mathrm{~d}, 3 \mathrm{H}, J=6.3 \mathrm{~Hz},\left(\mathrm{CH}_{3}\right)_{2} \mathrm{CH}\right) ;{ }^{13} \mathrm{C} \mathrm{NMR}\left(75 \mathrm{MHz}, \mathrm{CDCl}_{3}\right) \delta 171.4,166.8,153.4$, $132.5,131.6,130.5,128.4,127.7,126.8,124.1,106.5,68.7,67.2,56.0,36.0,28.6,21.9,21.6$; IR (thin film) 3287, 2981, 2951, 2854, 2813, 1727, 1650, 1618, 1504, 1468, 1454, 1281, 1222, 1199, 1108, 712 $\mathrm{cm}^{-1}$; HRMS (FAB+) calcd for $\mathrm{C}_{21} \mathrm{H}_{24} \mathrm{~N}_{3} \mathrm{O}_{3}: 366.1818\left([\mathrm{M}-\mathrm{H}]^{+}\right)$, found $366.1827\left([\mathrm{M}-\mathrm{H}]^{+}\right)$.

Table 1, Entry 8: (S)-( $N$ '-Benzoyl-hydrazino)-(1-methyl-1,2,3,4-tetrahydro-quinolin-6-yl)-acetic acid iso-propyl ester: (87\% ee, see below for assay) $[\alpha]^{26}{ }_{\mathrm{D}}=+76.2^{\circ}\left(c 1.0, \mathrm{CHCl}_{3}\right) ;{ }^{1} \mathrm{H} \mathrm{NMR}(300 \mathrm{MHz}$, $\left.\mathrm{CDCl}_{3}\right) \delta 7.98(\mathrm{br} \mathrm{s}, 1 \mathrm{H}, \mathrm{NHBz}), 7.72(\mathrm{~d}, 2 \mathrm{H}, J=7.3 \mathrm{~Hz}, \mathrm{Ar}-\mathbf{H}), 7.51$ (t, $\left.1 \mathrm{H}, J=7.3 \mathrm{~Hz}, \mathrm{Ar}-\mathbf{H}\right), 7.42(\mathrm{t}$, 
$2 \mathrm{H}, J=7.3 \mathrm{~Hz}, \operatorname{Ar}-\mathbf{H}), 7.10(\mathrm{dd}, 1 \mathrm{H}, J=2.1,8.4 \mathrm{~Hz}, \operatorname{Ar}-\mathbf{H}), 7.02(\mathrm{~d}, 1 \mathrm{H}, J=2.1 \mathrm{~Hz}, \operatorname{Ar}-\mathbf{H}), 6.53(\mathrm{~d}, 1 \mathrm{H}$, $J=8.4 \mathrm{~Hz}$, Ar-H), 5.10 (br s, 1H, CHNH), 5.08 (sep, 1H, $\left.J=6.2 \mathrm{~Hz},\left(\mathrm{CH}_{3}\right)_{2} \mathrm{CH}\right), 4.71$ (s, 1H, CHNH), $3.23\left(\mathrm{t}, 2 \mathrm{H}, J=6.1 \mathrm{~Hz}, \operatorname{Ar}-\mathrm{CH}_{2} \mathrm{CH}_{2} \mathrm{CH}_{2} \mathrm{~N}\right), 2.89(\mathrm{~s}, 3 \mathrm{H}, \mathrm{NCH}), 2.74(\mathrm{t}, 2 \mathrm{H}, J=6.1 \mathrm{~Hz}, \mathrm{Ar}-$ $\mathrm{CH}_{2} \mathrm{CH}_{2} \mathrm{CH}_{2} \mathrm{~N}$ ), 1.96 (quin, $2 \mathrm{H}, J=6.1 \mathrm{~Hz}, \mathrm{Ar}-\mathrm{CH}_{2} \mathrm{CH}_{2} \mathrm{CH}_{2} \mathrm{~N}$ ), 1.23 (d, 3H, $\left.J=6.2 \mathrm{~Hz},(\mathrm{CH})_{2} \mathrm{CH}\right), 1.15$ $\left(\mathrm{d}, 3 \mathrm{H}, J=6.2 \mathrm{~Hz},\left(\mathrm{CH}_{3}\right)_{2} \mathrm{CH}\right) ;{ }^{13} \mathrm{C} \mathrm{NMR}\left(75 \mathrm{MHz}, \mathrm{CDCl}_{3}\right) \delta 171.7,167.0,146.9,132.7,131.8,128.7$, 128.6, 127.1, 126.9, 122.8, 122.3, 110.7, 68.7, 66.9, 51.1, 39.0, 27.7, 22.2, 21.7, 21.5; IR (thin film) 3291, 2980, 2936, 1728, 1648, 1612, 1515, 1461, 1320, 1209, 1107, $699 \mathrm{~cm}^{-1}$; HRMS (FAB+) calcd for $\mathrm{C}_{22} \mathrm{H}_{26} \mathrm{~N}_{3} \mathrm{O}_{3}: 380.1974\left([\mathrm{M}-\mathrm{H}]^{+}\right)$, found $380.1970\left([\mathrm{M}-\mathrm{H}]^{+}\right)$.

Table 2, Entry 1: (S)-( $N^{\prime}$-Benzoyl-hydrazino)-(5-nitro-1H-indole-3-yl)-acetic acid iso-propyl ester: (88\% ee, see below for assay) $[\alpha]^{25}=+21.4^{\circ}\left(c 0.85, \mathrm{CHCl}_{3}\right),{ }^{1} \mathrm{H} \mathrm{NMR}\left(300 \mathrm{MHz}, \mathrm{CDCl}_{3}\right) \delta 9.23$ (br s, 1H, Ar-NHCH), 8.78 (d, 1H, $J=2.0 \mathrm{~Hz}, \mathrm{Ar}-\mathrm{H}), 8.13$ (br s, 1H, NHBz), 8.05 (dd, 1H, $J=2.0,8.9$ $\mathrm{Hz}, \operatorname{Ar}-\mathbf{H}), 7.73$ (d, 2H, J=7.2 Hz, Ar-H), 7.52 (t, 1H, J= 7.2 Hz, Ar-H), 7.43 (t, 2H, J = 7.2 Hz, Ar-H), 7.35-7.38 (m, 2H, Ar-H), 5.29 (br s, 1H, CHNH), 5.16 (s, 1H, CHNH), 5.09 (sep, 1H, J = 6.2 Hz, $\left.\left(\mathrm{CH}_{3}\right)_{2} \mathrm{CH}\right), 1.26\left(\mathrm{~d}, 3 \mathrm{H}, J=6.2 \mathrm{~Hz},\left(\mathrm{CH}_{3}\right)_{2} \mathrm{CH}\right), 1.10\left(\mathrm{~d}, 3 \mathrm{H}, J=6.2 \mathrm{~Hz},\left(\mathrm{CH}_{3}\right)_{2} \mathrm{CH}\right) ;{ }^{13} \mathrm{C} \mathrm{NMR}(75 \mathrm{MHz}$, $\left.\mathrm{CDCl}_{3}\right) \delta 170.8,167.5,142.0,139.2,132.3,132.2,128.8,127.0,126.9,125.4,118.1,117.3,112.9,111.5$, 69.6, 60.2, 21.7, 21.5; IR (thin film) 3286, 2979, 2930, 1725, 1652, 1515, 1470, 1333, 1235, 1203, 1102, 754, 742, $693 \mathrm{~cm}^{-1}$; LRMS (FAB+) calcd for $\mathrm{C}_{20} \mathrm{H}_{21} \mathrm{~N}_{4} \mathrm{O}_{5}: 397\left([\mathrm{M}+\mathrm{H}]^{+}\right)$, found $397\left([\mathrm{M}+\mathrm{H}]^{+}\right)$.

Table 2, Entry 2: (S)-(N'-Benzoyl-hydrazino)-(1-benzyl-1H-pyrrol-2-yl)-acetic acid iso-propyl ester: ( $88 \%$ ee, see below for assay) $[\alpha]^{25}=+38.6^{\circ}\left(c 1.1, \mathrm{CHCl}_{3}\right) ;{ }^{1} \mathrm{H} \mathrm{NMR}\left(300 \mathrm{MHz}, \mathrm{CDCl}_{3}\right) \delta 8.13(\mathrm{~d}$, $1 \mathrm{H}, J=4.9 \mathrm{~Hz}, \mathrm{NHBz}), 7.68(\mathrm{~d}, 2 \mathrm{H}, J=7.3 \mathrm{~Hz}, \mathrm{Ar}-\mathbf{H}), 7.48(\mathrm{t}, 1 \mathrm{H}, J=7.3 \mathrm{~Hz}, \mathrm{Ar}-\mathbf{H}), 7.38(\mathrm{t}, 2 \mathrm{H}, J=$ 7.3 Hz, Ar-H), 7.18-7.27 (m, 3H, Ar-H), 7.05 (d, 2H, J=6.9 Hz, Ar-H), 6.66-6.67 (m, 1H, Ar-H), 6.16$6.17(\mathrm{~m}, 1 \mathrm{H}, \operatorname{Ar}-\mathbf{H}), 6.12(\mathrm{t}, 1 \mathrm{H}, J=3.1 \mathrm{~Hz}, \operatorname{Ar}-\mathbf{H}), 5.50\left(\mathrm{~d}, 1 \mathrm{H}, J=16.3 \mathrm{~Hz}, \operatorname{Ar}-\mathrm{CH}_{2}\right), 5.25(\mathrm{~d}, 1 \mathrm{H}, J=$ $\left.16.3 \mathrm{~Hz}, \mathrm{Ar}-\mathrm{CH}_{2}\right), 4.99$ (br s, 1H, CHNH), 4.97 (sep, 1H, J = 6.3 Hz, $\left.\left(\mathrm{CH}_{3}\right)_{2} \mathrm{CH}\right), 4.85$ (s, 1H, CHNH), $1.16\left(\mathrm{~d}, 3 \mathrm{H}, J=6.3 \mathrm{~Hz},\left(\mathrm{CH}_{3}\right)_{2} \mathrm{CH}\right), 1.13\left(\mathrm{~d}, 3 \mathrm{H}, J=6.3 \mathrm{~Hz},\left(\mathrm{CH}_{3}\right)_{2} \mathrm{CH}\right) ;{ }^{13} \mathrm{C} \mathrm{NMR}\left(75 \mathrm{MHz}, \mathrm{CDCl}_{3}\right) \delta$ $170.6,167.2$, 138.3 132.6, 131.8, 128.5, 127.3, 127.0, 126.5, 125.9, 123.4, 109.5, 107.9, 69.2, 59.7, 50.4, 21.6, 21.3; IR (thin film) 3296, 2980, 2934, 1732, 1654, 1480, 1454, 1311, 1214, 1106, 715, $693 \mathrm{~cm}^{-1}$; LRMS (FAB+) calcd for $\mathrm{C}_{23} \mathrm{H}_{26} \mathrm{~N}_{3} \mathrm{O}_{3}: 392\left([\mathrm{M}+\mathrm{H}]^{+}\right)$, found $392\left([\mathrm{M}+\mathrm{H}]^{+}\right)$. 
Table 2, Entry 3: (R)-(N'-Benzoyl-hydrazino)-(5-methoxy-thiophen-2-yl)-acetic acid iso-propyl ester: $\left(89 \%\right.$ ee, see below for assay) $[\alpha]^{29}{ }_{\mathrm{D}}=+70.2^{\circ}\left(c 1.0, \mathrm{CHCl}_{3}\right) ;{ }^{1} \mathrm{H} \mathrm{NMR}\left(300 \mathrm{MHz}, \mathrm{CDCl}_{3}\right) \delta 7.83$ (br s, 1H, NHBz), 7.68 (d, 2H, $J=7.3 \mathrm{~Hz}, \operatorname{Ar}-\mathbf{H}), 7.50$ (t, 1H, $J=7.3 \mathrm{~Hz}, \operatorname{Ar}-\mathbf{H}), 7.41(\mathrm{t}, 2 \mathrm{H}, J=7.3 \mathrm{~Hz}$, Ar-H), 6.74 (d, 1H, J = 3.8 Hz, Ar-H ), 6.05 (d, 1H, J=3.8 Hz, Ar-H), 5.33 (br s, 1H, CHNH), 5.08 (sep, $\left.1 \mathrm{H}, J=6.3 \mathrm{~Hz},\left(\mathrm{CH}_{3}\right)_{2} \mathrm{CH}\right), 4.97(\mathrm{~s}, 1 \mathrm{H}, \mathrm{CHNH}), 3.86\left(\mathrm{~s}, 3 \mathrm{H}, \mathrm{OCH}_{3}\right), 1.26(\mathrm{~d}, 3 \mathrm{H}, J=6.3 \mathrm{~Hz}$, $\left.\left(\mathrm{CH}_{3}\right)_{2} \mathrm{CH}\right), 1.20\left(\mathrm{~d}, 3 \mathrm{H}, J=6.3 \mathrm{~Hz},\left(\mathrm{CH}_{3}\right)_{2} \mathrm{CH}\right) ;{ }^{13} \mathrm{C} \mathrm{NMR}\left(75 \mathrm{MHz}, \mathrm{CDCl}_{3}\right) \delta 169.9,167.3,167.0,132.4$, $131.9,128.6,127.0,125.4,123.0,103.1,69.4,63.0,60.0,21.6,21.4$; IR (thin film) 3290, 2978, 2937 , 1732, 1659, 1503, 1431, 1311, 1213, 1104, 715, $694 \mathrm{~cm}^{-1}$; LRMS (FAB+) calcd for $\mathrm{C}_{17} \mathrm{H}_{19} \mathrm{~N}_{2} \mathrm{O}_{4} \mathrm{~S}: 347$ $\left([\mathrm{M}-\mathrm{H}]^{+}\right)$, found $347\left([\mathrm{M}-\mathrm{H}]^{+}\right)$.

Determination of absolute configuration: Ethyl ester 2 (71\% ee, see Scheme 2) was subjected to reduction with $\mathrm{SmI}_{2}$ to give amine $3\left([\alpha]^{26}=+56.2^{\circ}(c 1.0, \mathrm{MeOH})\right)$. Amine 3 is a known compound and the $R$-enantiomer $\left(93 \%\right.$ ee) gave: $[\alpha]_{\mathrm{D}}^{20}=-91.9^{\circ}\left(c\right.$ 1.0, MeOH). ${ }^{1}$ Our compound is therefore $S$, and all other products were assigned as $S$ by analogy, except the product from Table 2, entry 3, which is $R$.

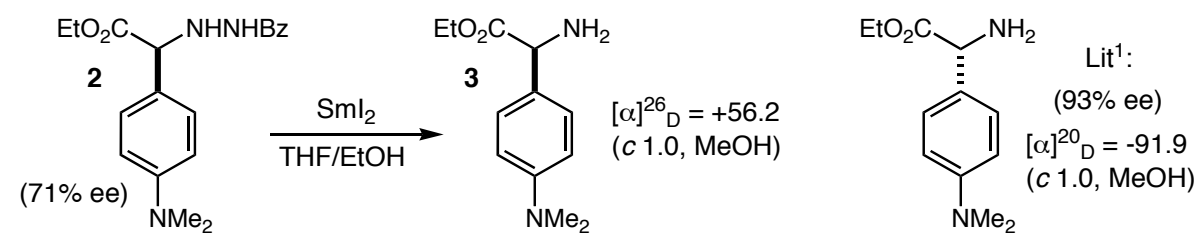

(1) Saaby, S.; Fang, X.; Gathergood, N.; Jørgensen, K. A. Angew. Chem. Int. Ed. 2000, 39, 4114. 
Determination of enantiomeric excess (ee) for the products in Table 1 and Table 2: All ees were determined by chiral HPLC analysis.

Table 1, entry 1: DAICEL Chiralpak AD-H, hexane $/ i-\mathrm{PrOH}=93 / 7,1.0 \mathrm{~mL} / \mathrm{min}, 254 \mathrm{~nm}$.
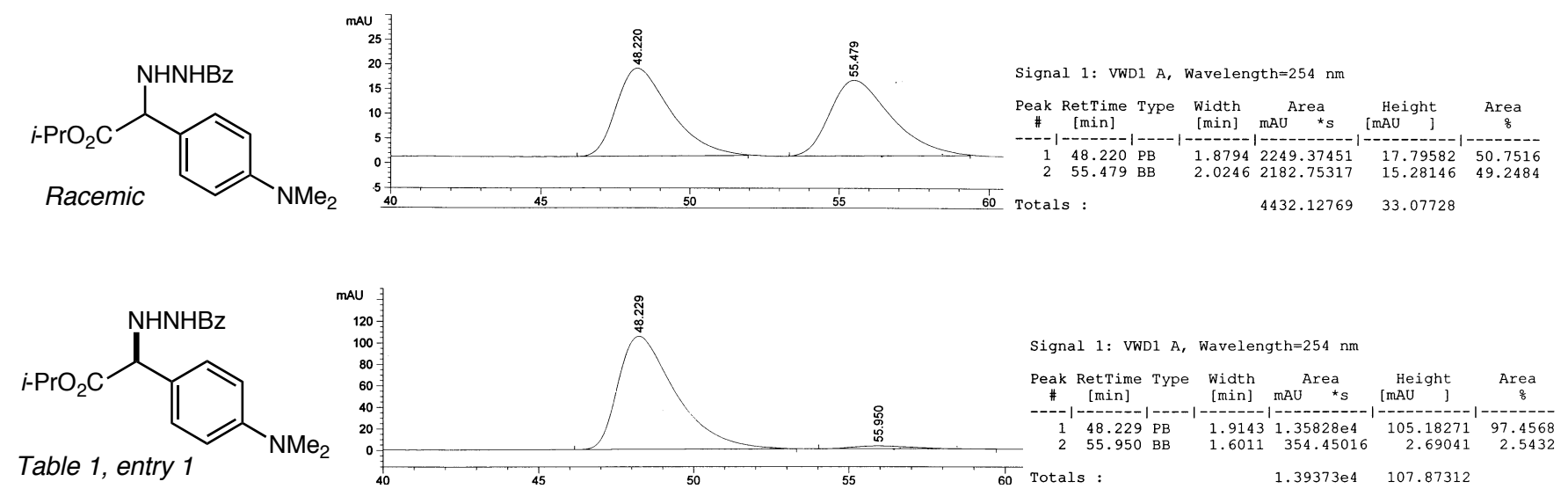

Table 1, entry 2: DAICEL Chiralpak AD-H, hexane $/ i$-PrOH = 93.5/6.5, $1.0 \mathrm{~mL} / \mathrm{min}, 254 \mathrm{~nm}$.
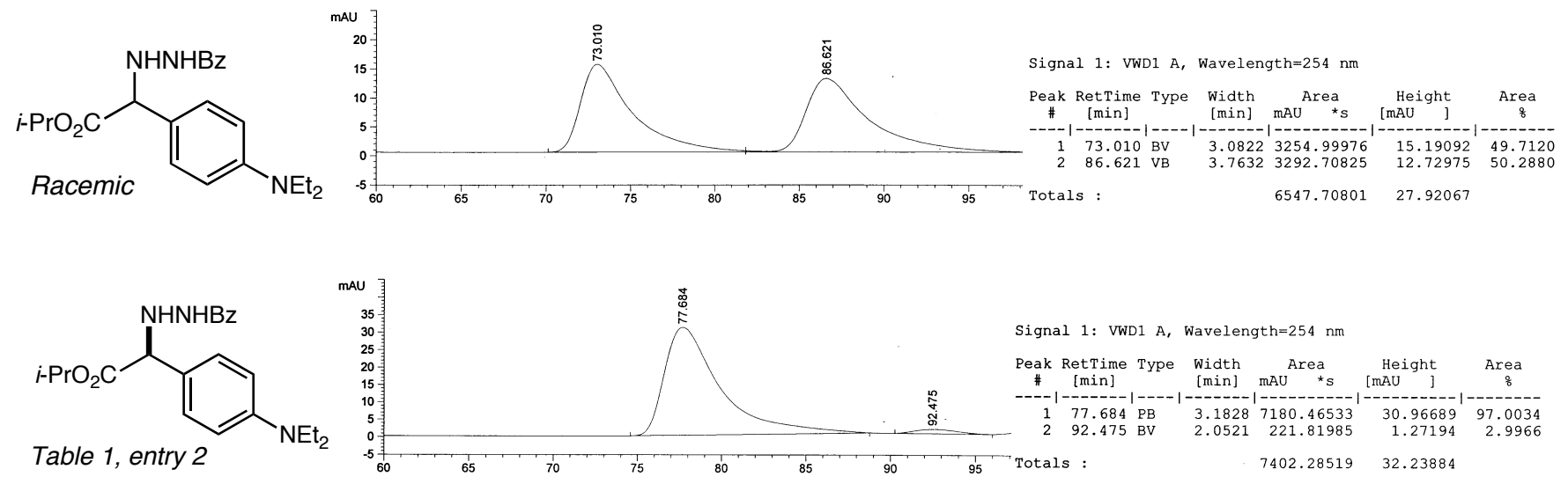

Table 1, entry 3: DAICEL Chiralpak AD-H, hexane/i-PrOH/EtOH = 80/10/10, $1.0 \mathrm{~mL} / \mathrm{min}, 254 \mathrm{~nm}$.
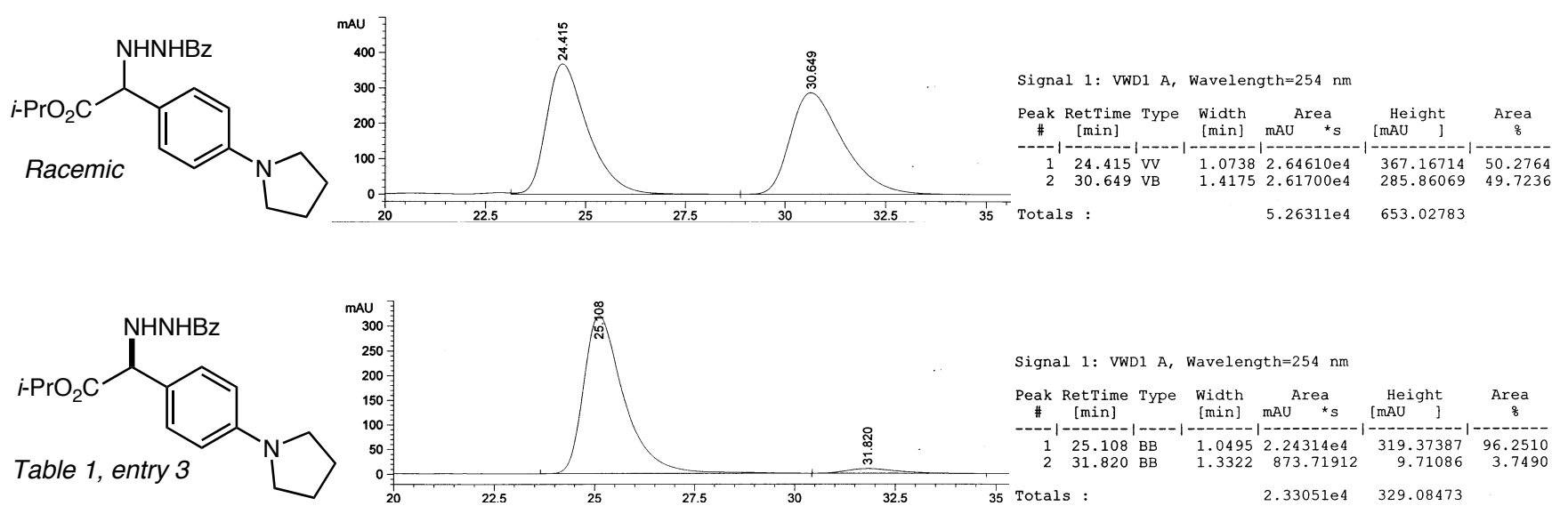
Table 1, entry 4: DAICEL Chiralpak AD-H, hexane $/ i-\mathrm{PrOH}=90 / 10,1.0 \mathrm{~mL} / \mathrm{min}, 254 \mathrm{~nm}$.
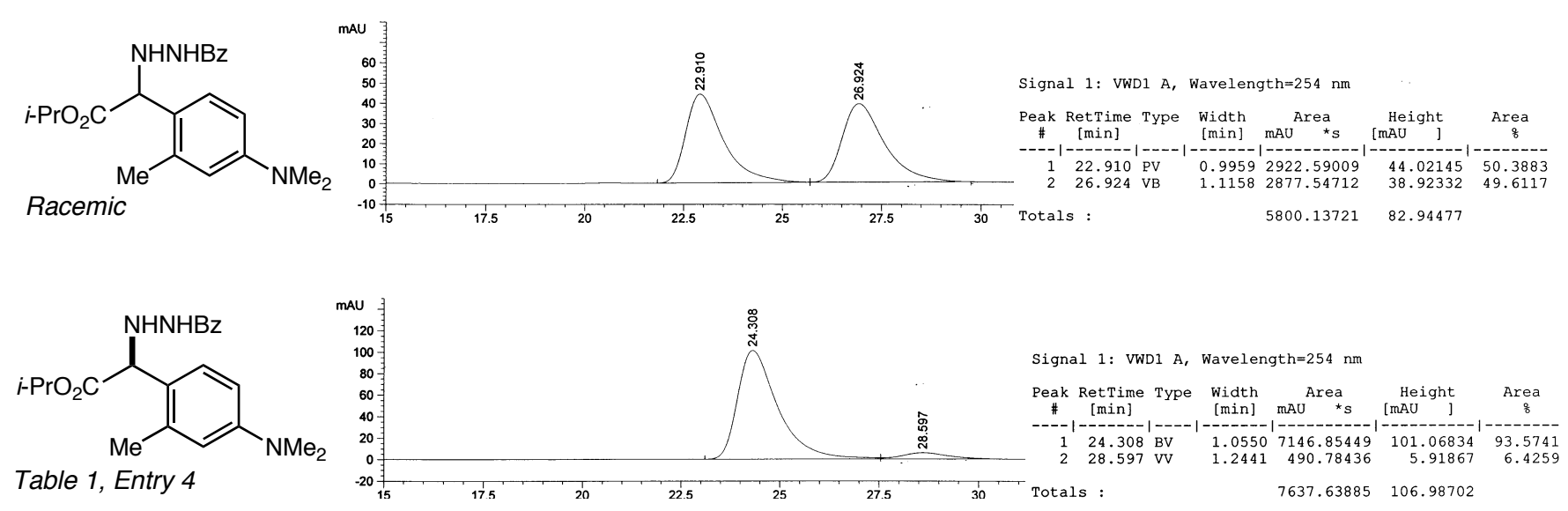

Table 1, entry 5: DAICEL Chiralpak AD-H, hexane $/ i-\mathrm{PrOH}=90 / 10,1.0 \mathrm{~mL} / \mathrm{min}, 254 \mathrm{~nm}$.
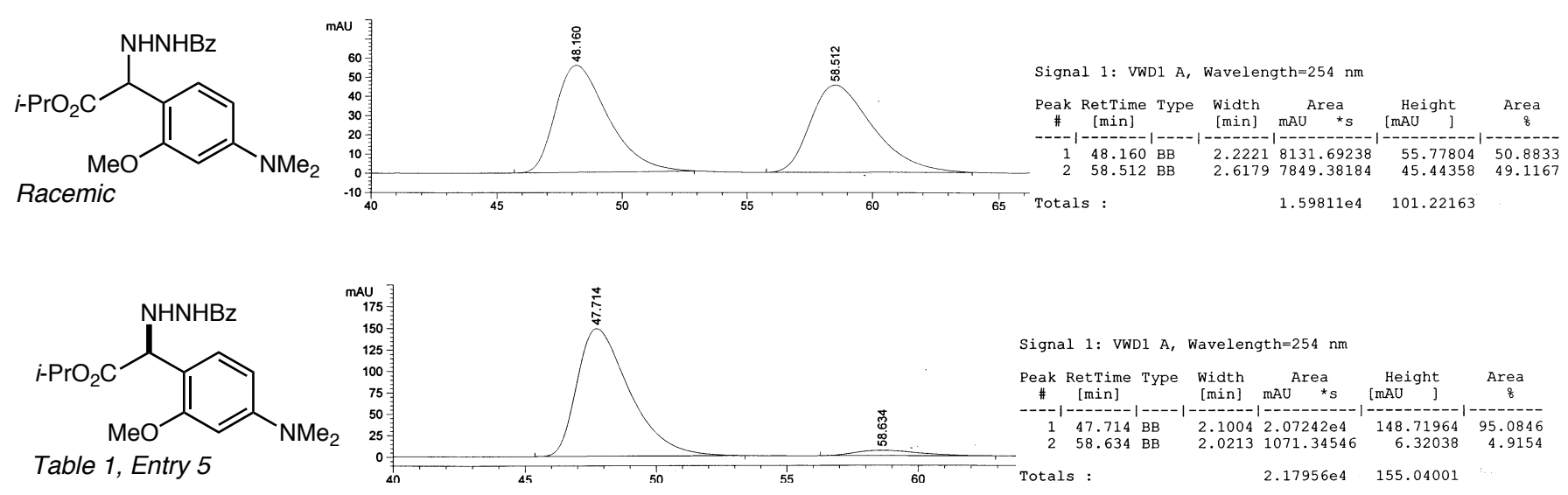

Table 1, entry 6: DAICEL Chiralpak AD-H, hexane $/ i-\mathrm{PrOH}=90 / 10,1.0 \mathrm{~mL} / \mathrm{min}, 254 \mathrm{~nm}$.
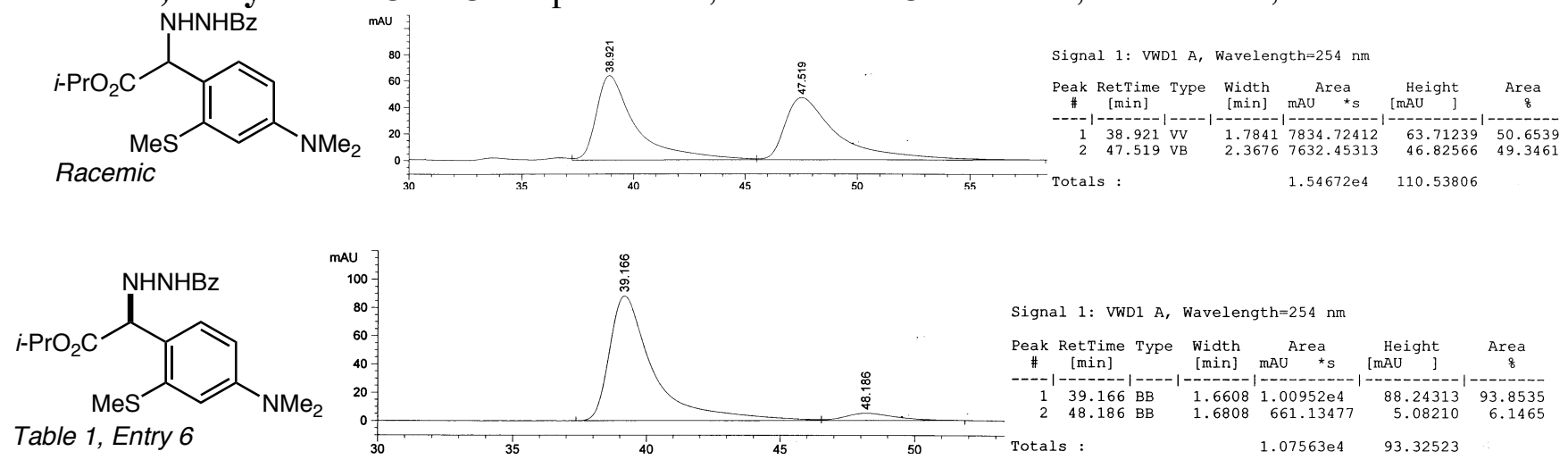
Table 1, entry 7: DAICEL Chiralpak AD-H, hexane $/ i-\mathrm{PrOH}=90 / 10,1.0 \mathrm{~mL} / \mathrm{min}, 254 \mathrm{~nm}$.
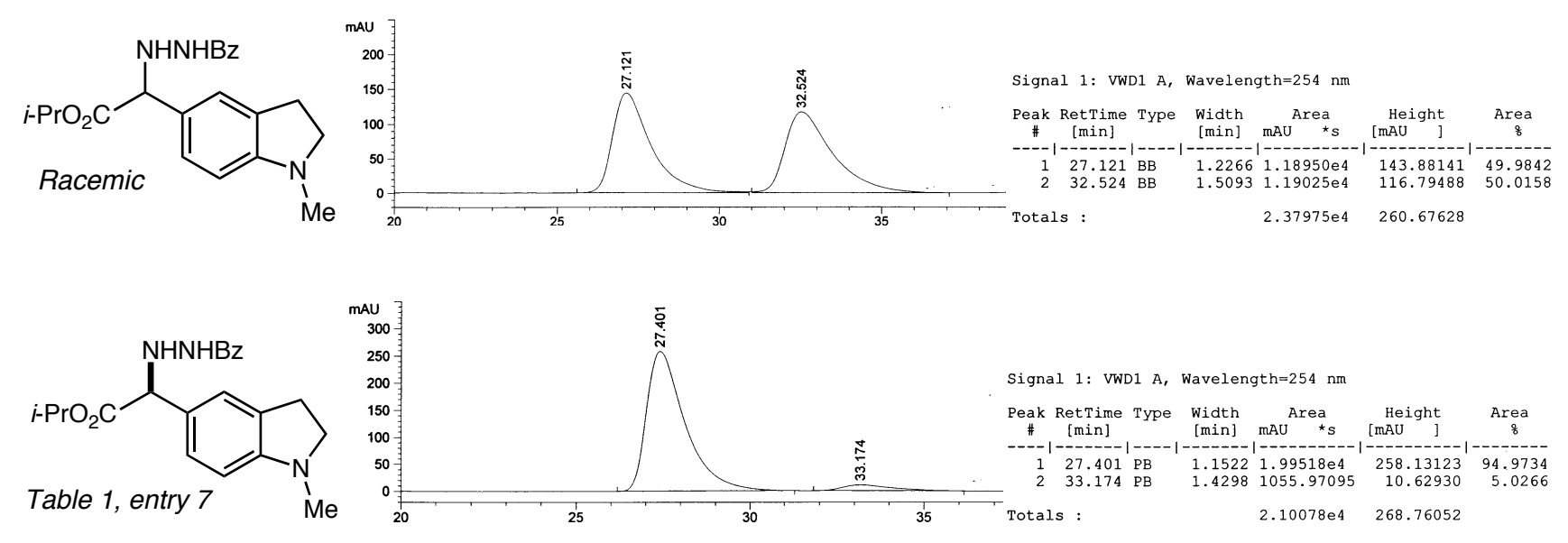

Table 1, entry 8: DAICEL Chiralpak AD-H, hexane $/ i-\mathrm{PrOH}=93 / 7,1.0 \mathrm{~mL} / \mathrm{min}, 254 \mathrm{~nm}$.
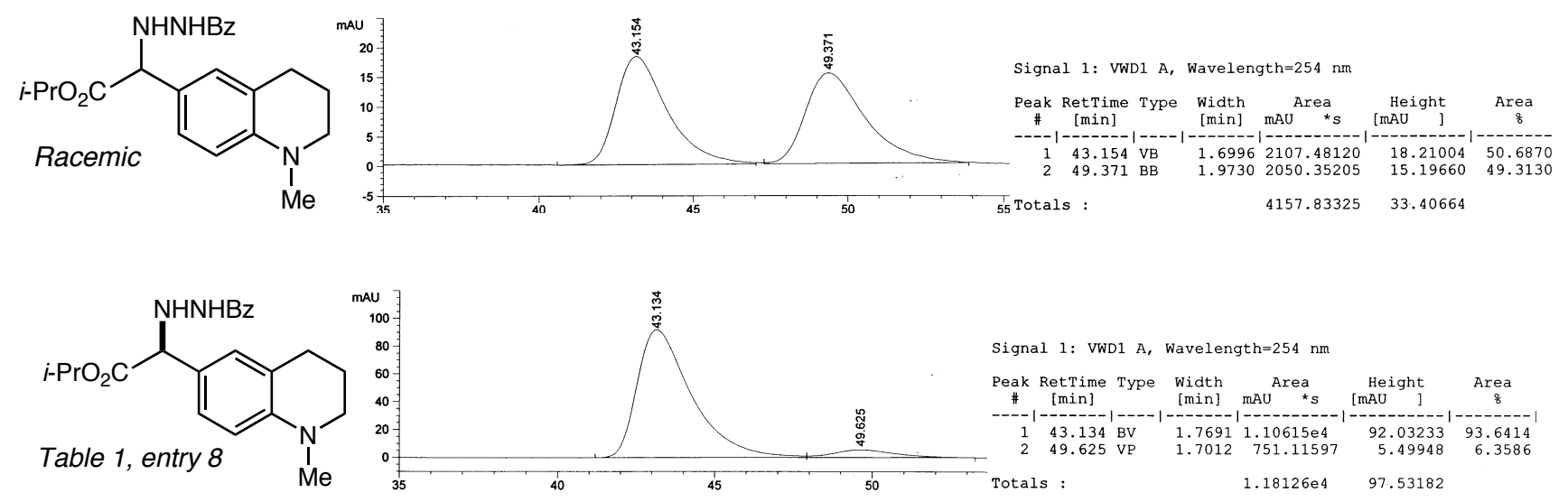

Table 2, entry 1: DAICEL Chiralpak AD-H, hexane $/ i-\mathrm{PrOH}=75 / 25,1.0 \mathrm{~mL} / \mathrm{min}, 254 \mathrm{~nm}$.
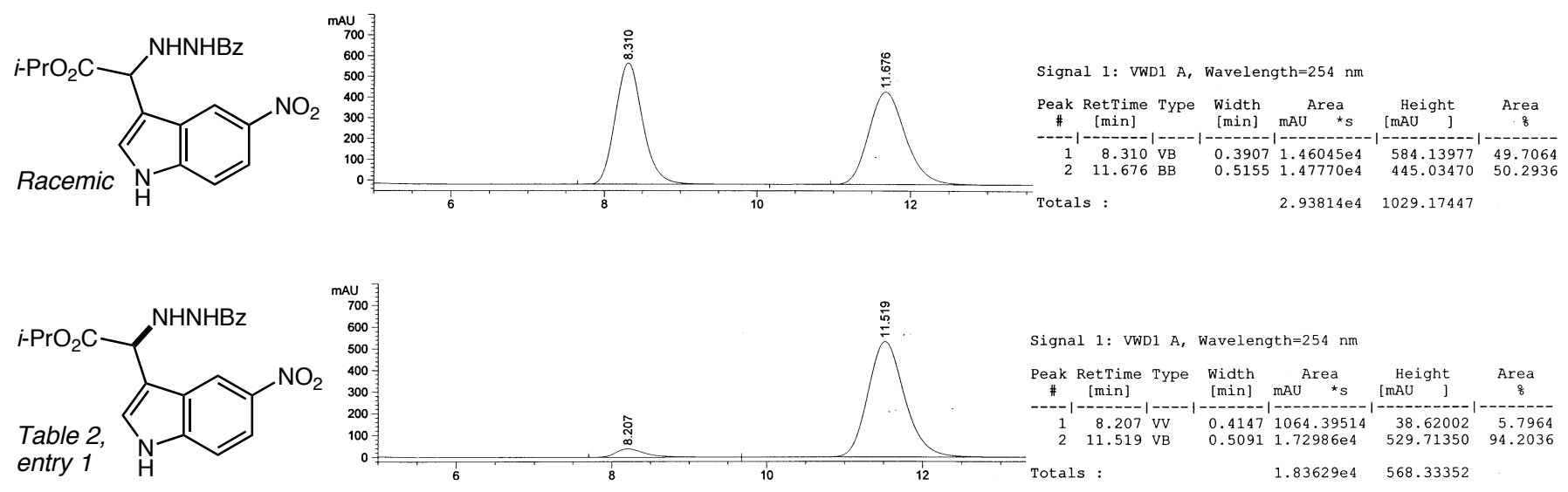
Table 2, entry 2: DAICEL Chiralpak AD-H, hexane/i-PrOH = 90/10, $1.0 \mathrm{~mL} / \mathrm{min}, 254 \mathrm{~nm}$.
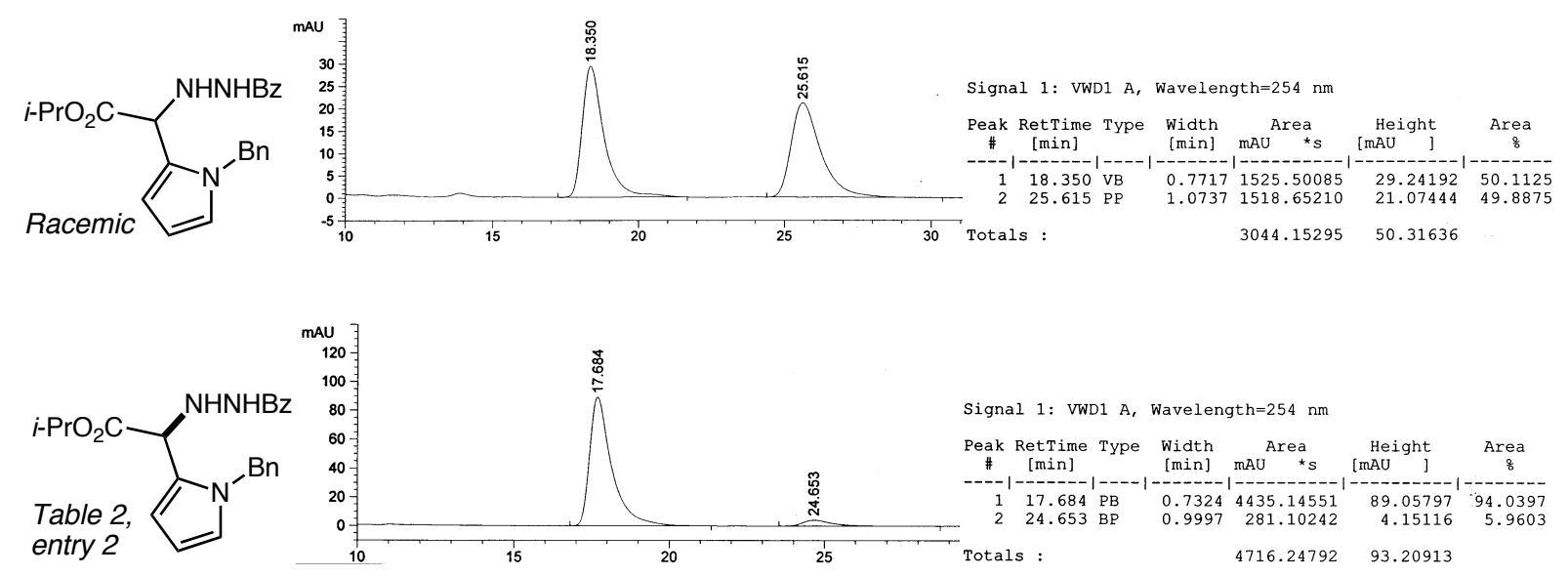

Table 2, entry 3: DAICEL Chiralcel OD, hexane/EtOH = 99/1, $1.0 \mathrm{~mL} / \mathrm{min}, 254 \mathrm{~nm}$.
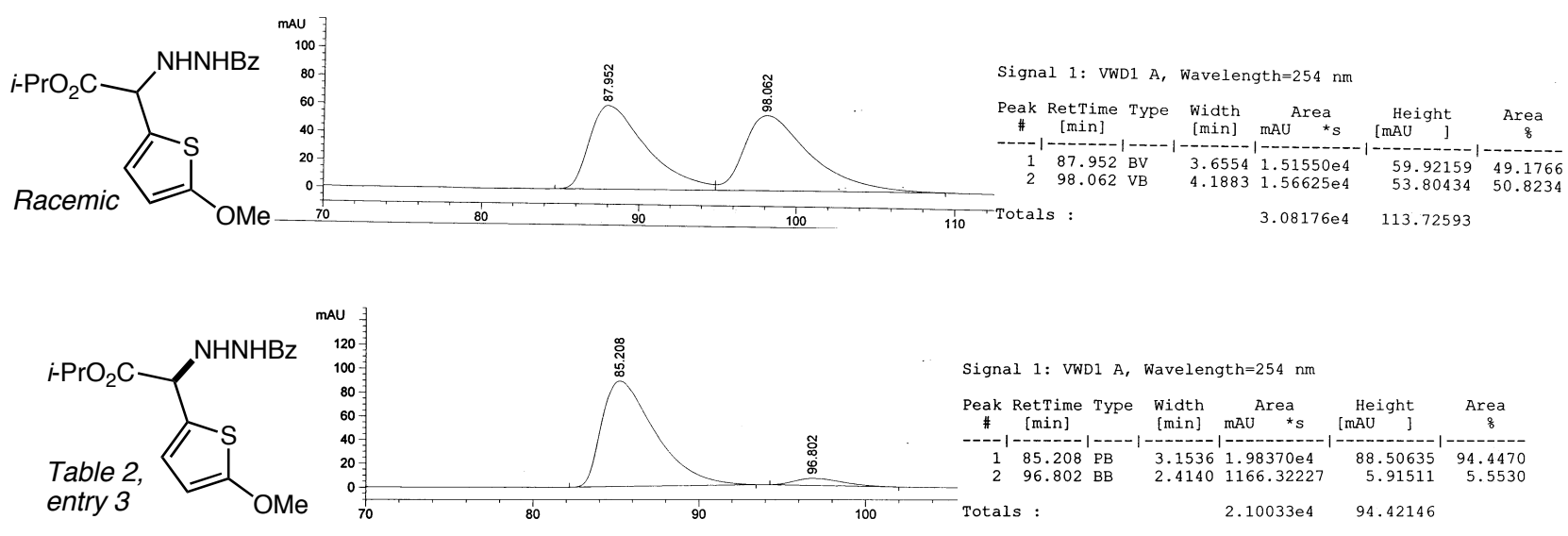

Scheme 3: DAICEL Chiralpak AD-H, hexane $/ i$-PrOH = 90/10, $1.0 \mathrm{~mL} / \mathrm{min}, 254 \mathrm{~nm}$.
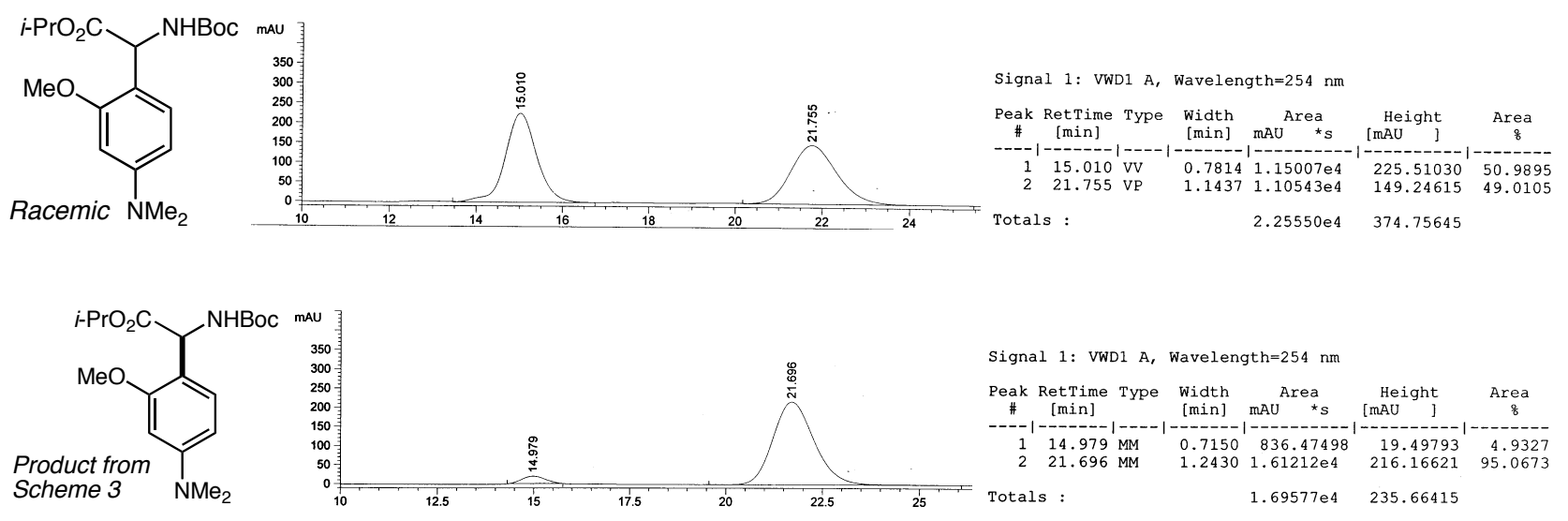
${ }^{1}$ H NMR Spectra of the products in Table 1, Table 2, and Scheme 3:
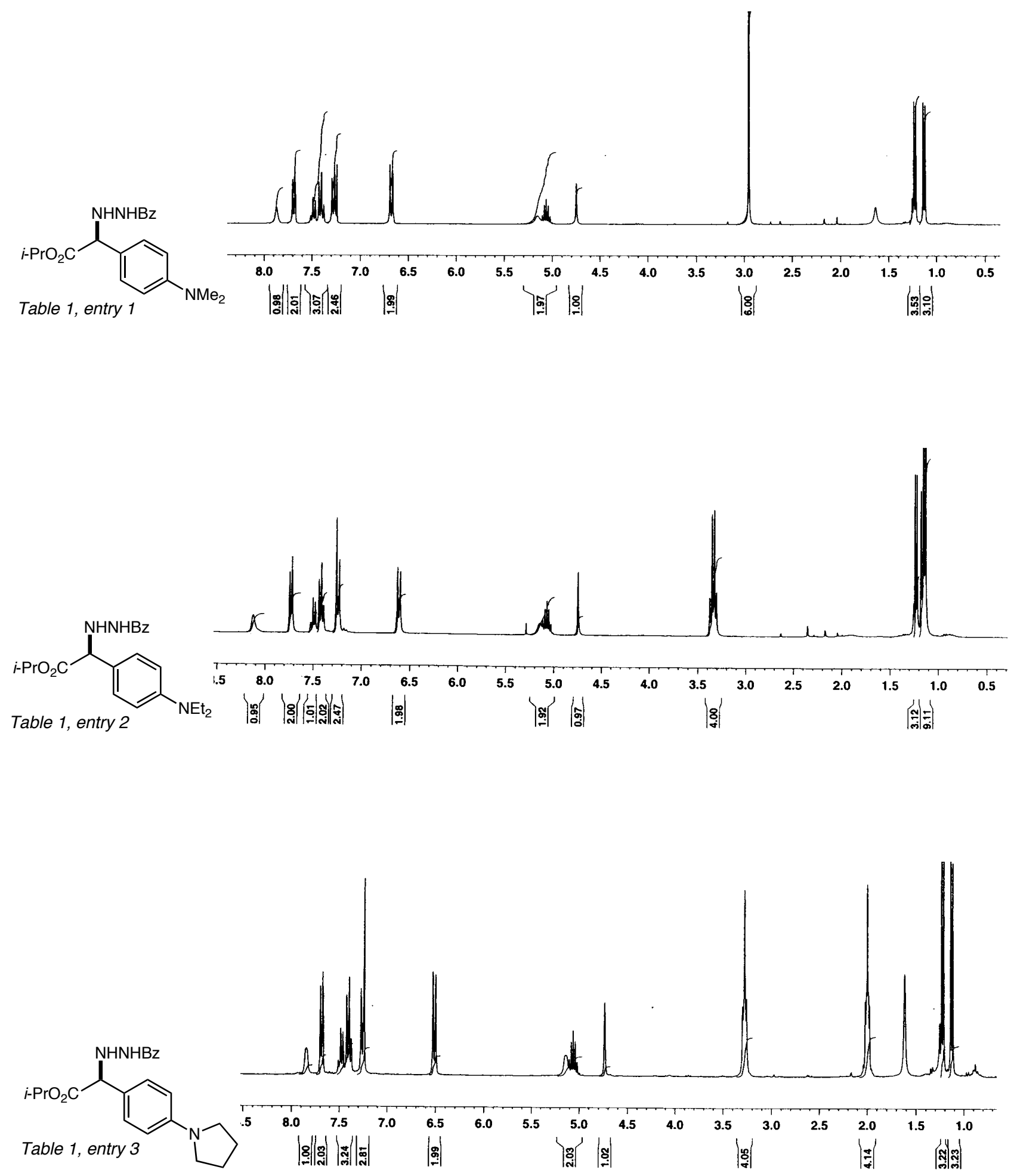
Page S15
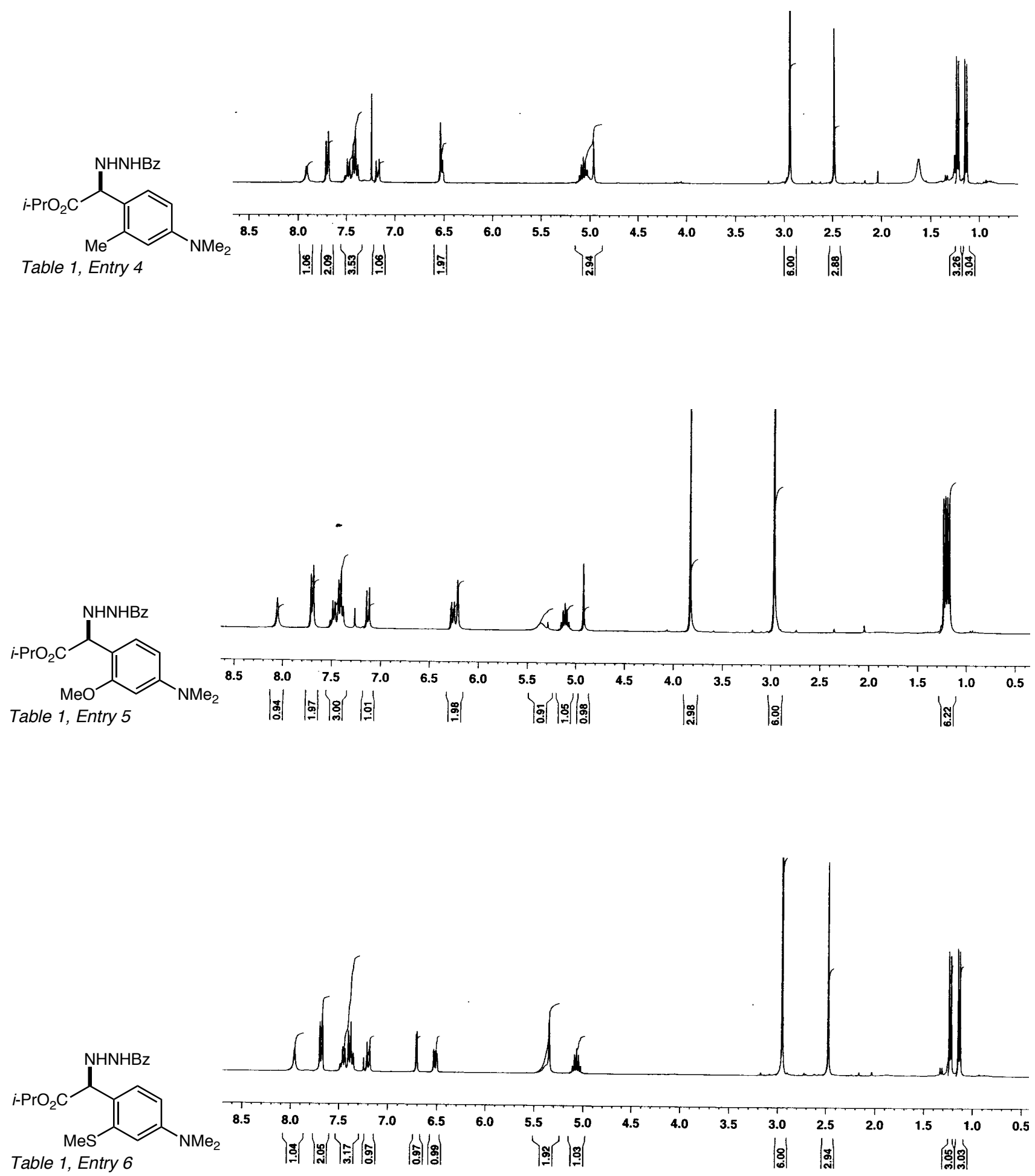
Page S16
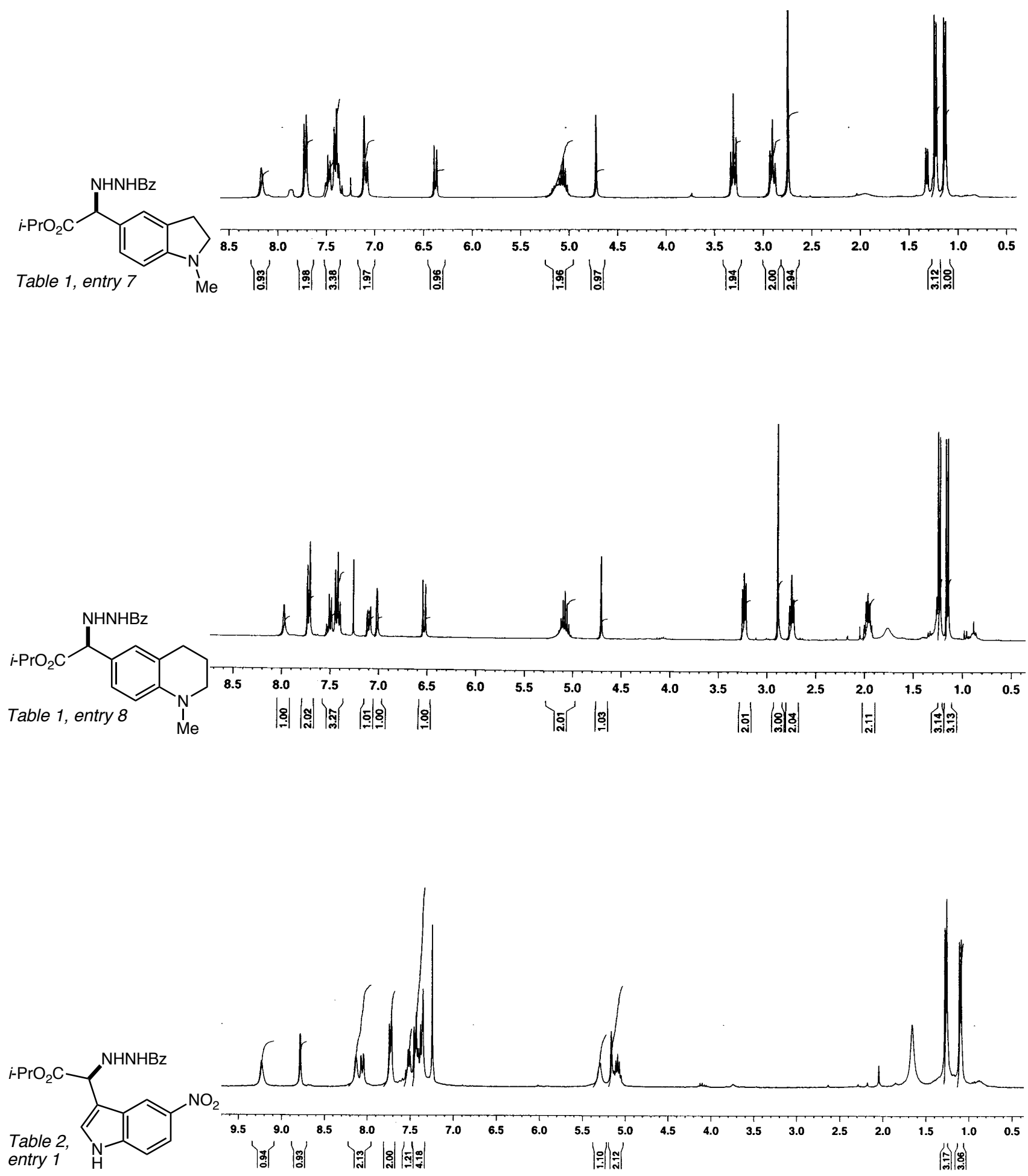

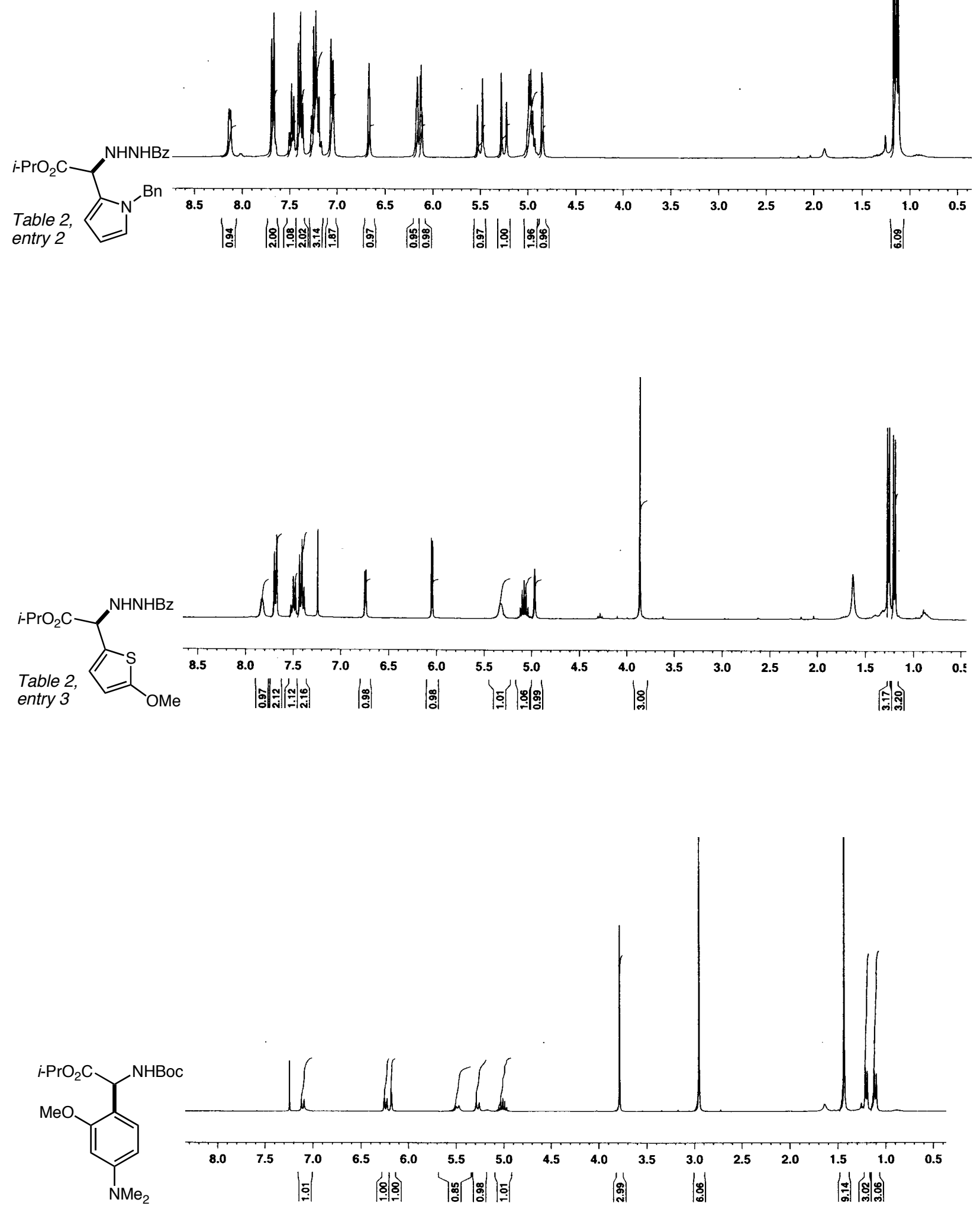